\title{
Interactions Between Inorganic and Organic Phases in Bone Tissue as a Source of Inspiration for Design of Novel Nanocomposites
}

\author{
Kambiz Farbod, MSc, M. Reza Nejadnik, PhD, John A. Jansen, DDS, PhD, \\ and Sander C.G. Leeuwenburgh, PhD
}

\begin{abstract}
Mimicking the nanostructure of bone and understanding the interactions between the nanoscale inorganic and organic components of the extracellular bone matrix are crucial for the design of biomaterials with structural properties and a functionality similar to the natural bone tissue. Generally, these interactions involve anionic and/or cationic functional groups as present in the organic matrix, which exhibit a strong affinity for either calcium or phosphate ions from the mineral phase of bone. This study reviews the interactions between the mineral and organic extracellular matrix components in bone tissue as a source of inspiration for the design of novel nanocomposites. After providing a brief description of the various structural levels of bone and its main constituents, a concise overview is presented on the process of bone mineralization as well as the interactions between calcium phosphate $(\mathrm{CaP})$ nanocrystals and the organic matrix of bone tissue. Bioinspired synthetic approaches for obtaining nanocomposites are subsequently addressed, with specific focus on chemical groups that have affinity for CaPs or are involved in stimulating and controlling mineral formation, that is, anionic functional groups, including carboxyl, phosphate, sulfate, hydroxyl, and catechol groups.
\end{abstract}

\section{Introduction}

A LTHOUGH BONE IS GENERALLY regarded as the toughest tissue in the body, it can be damaged due to either traumatic or nontraumatic causes. ${ }^{1}$ Autografts (tissue from patient's own body), allografts (tissue from another individual), and xenografts (tissue from a different species) are the conventional choices for treating bone defects ${ }^{1}$; autografts are still considered as the clinical gold standard for treatment of critical-sized ${ }^{2}$ bone defects. ${ }^{1,3,4}$ However, complications such as limited availability, additional surgeries, donor-site morbidity, ${ }^{5}$ and thus decreased quality of life for patients $^{6}$ still remain problematic. ${ }^{1,3}$ These limitations prompted the search for appropriate alternatives, resulting in several synthetic biomaterials (alloplasts), including metals, ${ }^{7}$ ceramics, ${ }^{8}$ polymers, ${ }^{9}$ and composites thereof. ${ }^{4}$ Despite their advantages and widespread clinical applications, these alloplasts are also associated with considerable drawbacks. In general, synthetic materials do not resemble or function like natural bone tissue, primarily due to lack of adequate tissue formation in the vicinity of the biomaterial immediately after implantation. ${ }^{1}$ Metallic biomaterials do not have the potential for drug delivery, do not degrade ${ }^{4}$ (with the exception of magnesium and its alloys ${ }^{10-12}$ ), and generally display elastic moduli significantly higher than bone, which can cause stress shielding. ${ }^{13,14}$ Such a stiffness mismatch causes inadequate load transfer from the biomaterial to the native bone tissue, ${ }^{14}$ which leads to complications such as bone resorption, ${ }^{13}$ and inflammation due to abrasive particles and leached toxic ions. ${ }^{15,16}$ Ceramic biomaterials are generally nonresilient ${ }^{17}$ and very brittle, ${ }^{4,16}$ which makes them prone to mechanical failure, ${ }^{4}$ whereas the majority of polymeric biomaterials are not osteoconductive. ${ }^{18}$ By benefitting from the favorable properties of each component (e.g., formability of polymers and strong mechanical properties of ceramic fillers) ${ }^{18}$ and eliminating their unfavorable properties, polymer-filler composites offer a solution to overcome some of the aforementioned drawbacks. ${ }^{19}$ Microstructured composites have been extensively investigated during the last two decades by including calcium phosphate $(\mathrm{CaP})$ microparticles into biodegradable polymers, such as collagen, gelatin, chitosan, and poly(lactic-co-glycolic acid). ${ }^{20-26}$ However, given that bone is a hierarchically structured nanocomposite comprised hydroxyapatite (HA) nanocrystallites dispersed in an organic matrix, it is perceived that biomaterials with similar hierarchical nanocomposite structures ${ }^{27}$ can offer improved functional and biological properties in comparison with conventional microstructured biomaterials or composites. ${ }^{1}$

Properties of composites are controlled by the properties of the matrix and dispersed phases as well as the interfacial

Department of Biomaterials, Radboud University Nijmegen Medical Centre, Nijmegen, The Netherlands. 
interactions between the two phases. As the size of the dispersed phase decreases, the significance of these interfacial interactions increases. As a consequence, properties of nanocomposites cannot be predicted anymore by applying the rule of mixtures since the composite properties are largely controlled by the interfacial interactions. ${ }^{19,28}$ Hence, to mimic the nanocomposite structure of natural bone, a good understanding of the role of these interfacial interactions at the molecular and nanoscale level is essential. Therefore, in the current study, we have reviewed the interactions between mineral and organic extracellular matrix (ECM) components in both the native bone tissue as well as the synthetic, bioinspired, inorganic-organic nanocomposites developed for bone regeneration. The first part of this review provides a brief description of the bone structure and its constituents, followed by an overview of different mechanisms of bone mineralization, as well as a description of interactions between $\mathrm{CaP}$ nanoparticles and the organic matrix in the bone ECM. The second part of this review addresses bioinspired synthetic approaches to obtain nanocomposites, with specific focus on chemical groups that have affinity for CaPs or are involved in stimulating and controlling mineral formation, that is, anionic functional groups including carboxyl, phosphate, sulfate, hydroxyl, and catechol groups.

\section{Micro- and Nanostructure of Bone Tissue}

\section{Extracellular matrix}

The ECM of bone is a dynamic network composed of a vast variety of organic and inorganic constituents, including collagen, elastin, polysaccharides, and CaP nanocrystals. ${ }^{29-34}$ In addition to providing a template for cell attachment and proliferation, ECM molecules control cell behavior by regulating cell proliferation and differentiation ${ }^{31,35}$ through a.o. soluble growth factors and cytokines, which are stored at minute quantities in the bone ECM. ${ }^{29,32}$

Collagen. Among more than twenty reported human collagens, collagen type I is the most abundant protein present in bone tissue. ${ }^{36,37}$ Collagen has been regarded as a passive scaffold for nucleation of apatite through interactions with noncollagenous proteins (NCPs). ${ }^{36,38}$ However, Nudelman et al. ${ }^{39}$ recently substantiated a hypothesis ${ }^{40}$ suggesting that collagen is actively involved in controlling the mineralization of apatite by attraction of negatively charged polyanionstabilized prenucleation clusters into positively charged regions of collagen fibrils. ${ }^{39,41,42}$ Wang et al. ${ }^{27}$ also showed recently that type I collagen can initiate and direct the growth of carbonated apatite mineral in vitro in the absence of any other vertebrate ECM molecules of calcifying tissues. Moreover, they revealed that the collagen matrix affects the structural characteristics on an atomic scale, and controls the size and three-dimensional distribution of apatite. ${ }^{27}$

Noncollagenous proteins. Bone sialoprotein (BSP), osteonectin, osteopontin, and osteocalcin are the main structural NCPs of the bone ECM. ${ }^{29,36}$ The majority of NCPs contain a high density of aspartic acid (Asp) and glutamic acid (Glu) residues, which have high affinity for calcium ions $\left(\mathrm{Ca}^{2+}\right)$ due to their charged carboxyl groups. ${ }^{36}$

BSP is a phosphoprotein that contains several polyglutamic acid segments responsible for binding to apatite ${ }^{43}$ as well as an RGD (arginylglycylaspartic/Arg-Gly-Asp acid) integrin-binding sequence at its C-terminus. ${ }^{36,44-48}$ Osteonectin, an acidic protein rich in cysteine, is a glycoprotein present at high concentrations in bone tissue. Osteonectin is slightly phosphorylated, while many Asp and Glu residues are repeated throughout its structure. ${ }^{36}$ Osteopontin is a negatively charged protein of $\sim 300$ amino acid residues with a very high content of Asp and Glu residues ${ }^{49,50}$ such as specific sequences of nine consecutive Asp residues. ${ }^{36,45,51-53}$ Similar to the role of polyglutamic acid segments in BSP, ${ }^{43}$ the polyaspartic acid segments in osteopontin are responsible for the tight binding of the protein to HA. ${ }^{46,54-56}$ Osteopontin is an essential regulator of osteoclast activity, and its phosphorylation level directs the inhibition or nucleation of HA. $^{36,45,51,57}$ It is suggested that partially phosphorylated osteopontin can bind to mineral nuclei or small crystals and block crystal growth, but completely phosphorylated osteopontin can nucleate mineral at low concentrations. ${ }^{36}$ Osteocalcin, a 49 -amino acid residue molecule, ${ }^{58}$ is the most prevalent NCP within the extracellular bone matrix, which is synthesized only by osteoblasts. ${ }^{36,59-61}$ It has a high affinity for apatite, ${ }^{62,63}$ and interacts with HA using $\gamma$-carboxyglutamic acid residues. ${ }^{52}$ Osteocalcin normally limits bone formation without decreasing bone mineralization or resorption. ${ }^{36,61}$

Inorganic phase. HA is the major inorganic crystal phase in bone tissue. ${ }^{34}$ However, bone mineral does not consist solely of HA, since the apatitic mineral in bone tissue contains impurities such as carbonate ions that substitute the hydroxyl and phosphate groups. ${ }^{29}$ Apatitic bone mineral crystals are mainly platelets, the reported dimensions of which vary in literature with values ranging between 20$50 \mathrm{~nm}$ long, 15-30 nm wide, and 2-10 nm thick. ${ }^{29,36,37,39,64-66}$ Carbonate concentrations of $4-6 \%$ render bone HA poorly crystalline, calcium deficient, and carbonated. ${ }^{29,37}$ In addition to carbonate substituting for phosphate groups, other substitutions are also reported, such as potassium, magnesium, strontium, and sodium for $\mathrm{Ca}^{2+}$, and chloride and fluoride for hydroxyl groups. ${ }^{29}$ Except for fluoride-which mainly increases the crystallinity of apatite-impurities generally reduce the crystallinity. As a consequence, bone mineral becomes more soluble, which is essential for mineral homeostasis and bone remodeling. ${ }^{29}$

\section{Interactions Between CaP Nanoparticles and Organic Matrix in the Bone ECM}

A wide variety of models have been proposed to describe the complex process of collagen mineralization, but none of them has completely captured all the known information, ${ }^{37}$ and controversies among researchers still exist regarding the mechanism of mineralization, the role of gap zones in collagen fibrils, and the shape of crystals in bone. In the following section, classical theories on $\mathrm{CaP}$ mineralization are reviewed first, followed by a separate section, which addresses recently obtained insights on mineralization.

\section{Classical theories on $\mathrm{CaP}$ mineralization}

According to classical theories on $\mathrm{CaP}$ mineralization, NCPs such as BSP, osteocalcin, and osteonectin are strongly and actively involved in the matrix mineralization 
process. ${ }^{36,67,68}$ In the early 1990s, Hunter and Goldberg ${ }^{45}$ hypothesized that the mineralization effects of BSP are exclusively related to acidic, glutamate-rich peptide sequences, and proposed that the removal of the phosphate groups on BSP has a minor or no effect on mineralization. In a later study, Stubbs et al. ${ }^{69}$ argued that groups other than acidic glutamate residues (such as phosphate, sulfate, and sialic acid groups) are also involved in mineral formation, and $\mathrm{He}$ et al. ${ }^{70}$ showed that phosphorylation is an essential factor for mineralization of phosphophoryn. Monfoulet et al..$^{71}$ showed that BSP acts as a crystal nucleator. In the late 1990s, osteocalcin and osteonectin were reported to regulate the size and speed of crystal formation. ${ }^{72}$ In the early 2000s, Hoang et al. ${ }^{73}$ proposed that proteins such as osteocalcin exhibit a specific mechanism for recognition of mineral surfaces that allows for biological adjustment of mineral crystal growth. Osteopontin, on the other hand, was found ${ }^{74,75}$ to influence the type of formed crystals and promote pathologic mineralization in cartilage. In the late 2000s, Elangovan et al. ${ }^{76}$ suggested that complexes can also be formed between backbone carbonyls of proline residues and $\mathrm{Ca}^{2+}$ in the inorganic phase.

The role of NCPs in the mineralization of collagen has been extensively studied, resulting into several models. According to one of the most popular models, the acidic NCPs exclusively bind to collagen molecules in the gap zonewhich is defined as a $40 \mathrm{~nm}$ zone containing only four molecules and $20 \%$ less packing density than the overlap zones of $27 \mathrm{~nm}$ containing five molecules, within the $67 \mathrm{~nm}$ periodic displacement pattern of collagen molecules ${ }^{36,66,77,78}$-and induce crystal nucleation inside the collagen fibrils. ${ }^{79}$ This theory is supported by the hypothesis that the initial mineral is deposited in the gap zones and that many noncollagenous acidic molecules bind specifically to collagen in these zones. ${ }^{80-82}$ Moreover, chains of nanometer-sized mineral nucle $^{83,84}$ fuse together to form elongated initial crystals, with their $c$-axes aligned with the long axes of the collagen fibrils, proposing epitaxial relationships between noncollagenous acidic proteins bound to the collagen fibrils and forming mineral. Nevertheless, this theory does not address the presence of transient amorphous calcium phosphate (ACP) in bone tissues. ${ }^{37}$ Another theory that is based on the phenomenon of size exclusion proposes that large acidic noncollagenous molecules inhibit mineralization outside the collagen fibrils, whereas their penetration into the gap zones is inhibited by their too large size. ${ }^{85}$ Consequently, the crystal growth is inhibited everywhere except inside the collagen fibril, resulting in initial mineral precipitation in the gap zones within the fibrils. This hypothesis, however, does not address the fact that the crystallites in the fibril are all coaligned. In addition, this model is unable to justify the presence of extrafibrillar crystallites, which encompass a large fraction of mineral in bone tissues. ${ }^{37}$ Another model proposes that mineral-protein complexes can form outside the collagen fibrils and subsequently diffuse inside, where they transform into the organized crystalline arrays guided by the collagen structure. ${ }^{86,87}$ This model suggests that the initial mineral formed is transient ACP stabilized in supramolecular assemblies of noncollagenous acidic proteins. These aggregates bind to collagen fibrils, which result in the transformation of the amorphous to crystalline phase. It is hypothesized that the NCPs in these protein-mineral aggregates interact with collagen molecules. Such interactions can influence the protein conformation, resulting in changes in its function from stabilizing ACP to controlling crystal nucleation. Already in the early 1990s, it was suggested $^{66,88}$ that a liquid protein-ACP phase infiltrates the collagen fibrils through capillary forces, filling the gap regions and the spaces between the triple helices and subsequently transforms into oriented crystals. These studies proposed that collagen molecules themselves actively direct the nucleation of oriented crystals.

According to the classical theories, nucleation of inorganic minerals is considered to occur in supersaturated solutions of their constituting ions, resulting in the nucleation of the solid phase by stochastic solute clustering, and a cluster of critical size is regarded as the initial crystal precursor. ${ }^{89,90}$ Due to this formation mechanism, such metastable clusters are a rare species, ${ }^{90}$ which only become stable when a critical size is reached at which the growing surface energy associated to the increasing surface area is balanced by the decrease in bulk energy associated to the formation of a crystal lattice. The resulting nanoparticles form the critical crystal nuclei, which are the starting point for further growth through the associated reduction of the Gibbs free energy of the system. ${ }^{89}$

\section{New insights on $\mathrm{CaP}$ mineralization}

In contrast to classical theories on biomineralization, Gebauer et al. ${ }^{89}$ showed that calcium-based biominerals can be formed through stable prenucleation clusters, which aggregate into an amorphous precursor phase that subsequently transforms into a crystal. ${ }^{41,90}$ In this regard, two studies performed by Sommerdijk and his coworkers ${ }^{39,91}$ further confirmed that $\mathrm{CaP}$ mineralization proceeds by means of prenucleation clusters. More specifically, Nudelman et al. ${ }^{39}$ reported on the influence of structure, assembly, and charge distribution of collagen on the formation of bone apatite and mineralization in the presence of polyaspartic acid as inhibitor for HA nucleation, thereby refuting the hypothesis supporting the passive role of collagen in nucleation of apatite for bone and tooth formation. ${ }^{39,41}$ In a related study, Dey et $a l .{ }^{91}$ revealed that the surface-induced formation of apatite from simulated body fluid (SBF) initiates with the aggregation of prenucleation clusters resulting in nucleation of ACP before the development of oriented apatite crystals. ${ }^{41}$ Fig. 1a schematically depicts the development of stable mineral droplets comprising CaP-biopolymer prenucleation clusters, which bind to distinct segments on collagen fibers and diffuse inside the fibril, where they solidify and transform into an amorphous phase. This amorphous phase is subsequently altered into oriented apatite crystals directed by the collagen fibril arrangement. ${ }^{68}$ Sommerdijk and his coworkers $^{92}$ recently revealed that $\mathrm{CaP}$ prenucleation clusters in fact are calcium triphosphate ion-association complexes that can aggregate into branched three-dimensional polymeric structures from which nucleation of ACP takes place through the simultaneous binding of calcium to form $\sim 1.2 \mathrm{~nm}$ postnucleation clusters, and their aggregation and precipitation as spherical particles. Continued calcium uptake converts ACP into octacalcium phosphate and subsequently into apatite. Measuring the rate of $\mathrm{CaP}$ nucleation as a function of supersaturation, it was shown that ACP formation cannot be directly reconciled with the classical 
nucleation theory. Nonetheless, theoretically, the thermodynamic barrier for nucleation is considerably decreased when the presence of prenucleation complexes and the particle size dependence of the interfacial free energy are taken into account. In summary, it was demonstrated that the presence of these complexes reduces the energy barrier to nucleation and proposes a so-called extended nucleation theory, which unites classical and nonclassical nucleation theories. ${ }^{92}$

Besides the above-mentioned and recently obtained insights on $\mathrm{CaP}$ mineralization, it should be noted that $\mathrm{CaP}$ mineralization in vivo proceeds according to a matrix vesiclemediated $^{93-95}$ mechanism. Matrix vesicle-mediated mineralization, on the other hand, is based on the formation of matrix vesicles by the outer membranes of osteoblasts, which act as compartmentalized microreactors for controlled precipitation of CaP nanocrystals. ${ }^{68,93}$ Three mechanisms have been proposed for the initiation of matrix vesicle-mediated mineralization (Fig. 1b) ${ }^{68,96}$ : (i) matrix vesicles only regulate ion concentrations, resulting in the development of soluble molecular species, which initiate mineral formation in collagen fibrils; (ii) matrix vesicles regulate ion concentrations, resulting in the development of intravesicular apatite crystals, which leave the vesicle and initiate the mineralization process; (iii) matrix vesicles link directly to collagen and facilitate matrix mineralization. ${ }^{68}$ As mentioned before, a wide range of NCPs are strongly involved in the matrix mineralization process. ${ }^{36,67,68}$ The enzyme alkaline phosphatase (ALP) is an important noncollageneous protein which, by hydrolyzing pyrophosphate (a mineralization inhibitor) and organic phosphate esters, ${ }^{97}$ provides phosphate ions $\left(\mathrm{PO}_{4}{ }^{3-}\right)$ to promote mineralization. ${ }^{68,98-100}$ Another phosphatase that is highly expressed in bone, PHOSPHO1, ${ }^{101}$ is present within matrix vesicles and has a role in the initiation of mineral formation. ${ }^{6,102}$

It has to be emphasized that the interactions between inorganic and organic components of bone at the molecular or nanoscale level influence the behavior of bone at the macroscopic scale as well. The exceptional toughness of the bone tissue appears to be related to the interactions between the anionic groups of the ECM proteins and the calcium ions provided by the inorganic phase. It has been shown that a large amount of energy can be dissipated due to the additional work required for the breaking of the reversible, calcium-mediated bonds (sacrificial bonds) in the organic network of the ECM. Osteopontin, in addition to other similar molecules present in bone such as BSP, can act as an interfacial glue through the network formation-a glue that dissipates energy through the sacrificial bond mechanism and can be used for improving the stiffness and toughness of synthetic nanoscale composites as well. ${ }^{54,55}$

\section{Interactions Between CaP Nanoparticles and Organic Matrix in Bioinspired Synthetic Nanocomposites}

A composite structure comprises at least two phases that are separated by interfaces. The characteristics of these interfaces - and thus of the composites - are highly affected by parameters such as the filler shape, size and size distribution, ratio between the filler and matrix, dispersion of filler particles in the matrix, and the interactions between the filler and matrix. ${ }^{103}$ Regarding the interactions between components, an inorganic phase can be introduced into an organic matrix through either covalent (irreversible) or noncovalent (reversible) bonds. Depending on these chemical interactions, Kickelbick ${ }^{104}$ classified the mutual arrangement of nanoparticles with polymer chains into four groups (Fig. 2): (i) dispersed inorganic particles in the organic continuous phase (blend); (ii) pendant inorganic groups bonded to the polymer backbone; (iii) interpenetrating network of inorganic components and polymers; (iv) dual inorganic-organic hybrid polymers, where covalent bonds exist between the two phases. ${ }^{103,105}$ This review mainly focuses on inorganicorganic composites (i.e., group one and two), which involve noncovalent bonds between the two phases. In addition to the classic polymer-ceramic nanocomposites (containing premade $\mathrm{CaP}$ nanoparticles), emerging approaches toward composite preparation by means of wet chemical mineralization of functionalized biomacromolecules have also been applied in the field of biomaterials and tissue engineering and will be addressed in this review as well, since these functionalized polymers have also become promising candidates for the preparation of polymer-ceramic nanocomposites with increased interaction between the mineral and organic phases. Notably, the number of studies investigating the inorganic-organic interactions in classic nanocomposites was considerably lower than the number of studies on wet chemical mineralization of (functionalized) polymers, which stresses the importance of bioinspired, wet chemical synthesis of composite materials.

There are a number of functional groups that show affinity for either calcium or phosphate ions present in different types of $\mathrm{CaP}$ (Fig. 3). As mentioned above, the rationale behind the use of different functional groups and molecules to obtain nanocomposites inspired by bone mineralization is based on (1) their affinity to adsorb to premade CaPs, or (2) their ability to trigger the process of nucleation by ionic interaction with either calcium or phosphate ions in the mineralization solution. Cationic functional groups with high affinity for phosphate mainly include amines but, due to the limited number of relevant studies, they are not addressed in this review. So far, the most commonly employed anionic functional groups with high affinity for $\mathrm{Ca}^{2+}$ are carboxyl, phosphate/phosphonate, sulfate, hydroxyl, and catechol groups. ${ }^{106}$ These chemical groups are widely employed in inorganic-organic interfaces of hybrid biomimetic nanocomposites to modify their ultimate properties, and will be separately described further in the following sections. Shen et al. ${ }^{107}$ carried out a systematic study on adsorption and desorption behavior of fibronectin on HA by steered molecular dynamics simulations, and reported that charged $-\mathrm{COO}^{-}$and $-\mathrm{NH}_{3}{ }^{+}$groups show the highest interaction energy with HA surfaces, with values ranging between 70 to $100 \mathrm{kcal} / \mathrm{mol}$. Hydroxyl groups revealed weaker interaction energies ranging about $43-45 \mathrm{kcal} / \mathrm{mol}$, whereas neutral amino groups exhibited interaction energies that were about half of charged $-\mathrm{NH}_{3}{ }^{+}$groups. Although these groups showed a weaker interaction with the surface compared to $-\mathrm{COO}^{-}$and $-\mathrm{NH}_{3}{ }^{+}$groups, it was revealed that they still considerably contribute to the total interaction energy between the proteins and HA surfaces. ${ }^{107}$

The following section highlights how anionic groups can be used to control the interfacial interactions between the organic and inorganic phases in nanocomposites, that is, how these chemical groups have been exploited for tissue 
a (i)

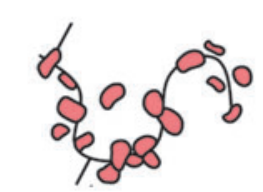

CaP Cluster-biopolymer Complex (ii)

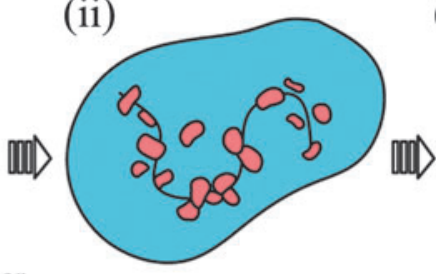

Stable Mineral

Droplet (iii)

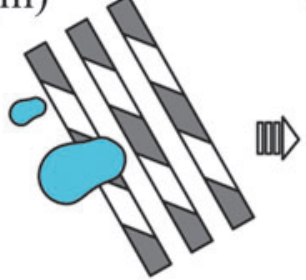

Binding to Distinct

Segments on

Collagen Fibers (iv)

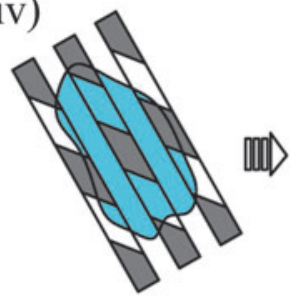

Diffusion inside Fibrils (v)

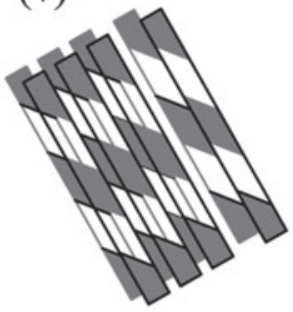

Solidifying and Mineralizing Fibril b

(i)

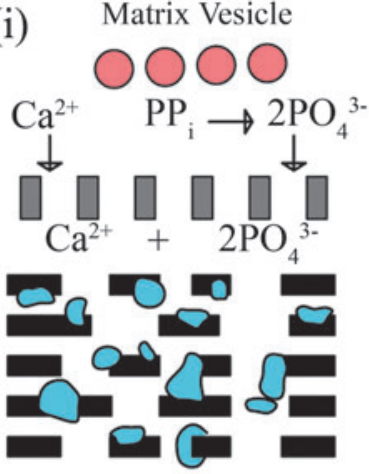

Collagen Fibril (ii)

$$
\begin{aligned}
& \mathrm{Ca}^{2+} \\
& \mathrm{PP}_{\mathrm{i}} \rightarrow 2 \mathrm{Ca}^{2+} \\
& 2 \mathrm{PO}_{4}^{3-}
\end{aligned}
$$
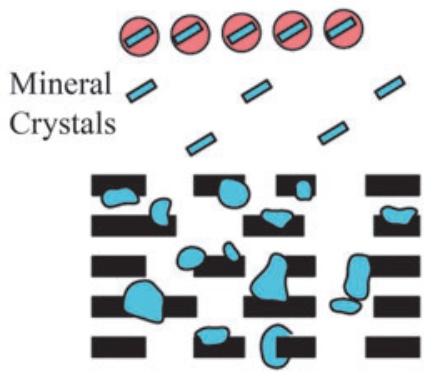

(iii)

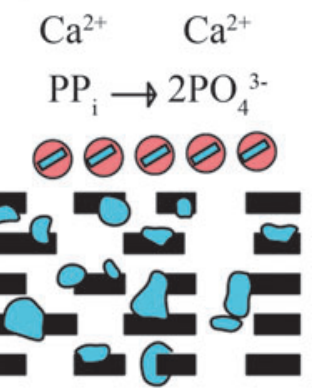

FIG. 1. According to new insights on calcium phosphate (CaP) mineralization, two simultaneously occurring processes account for biomineralization of collagen fibers. (a) Direct nucleation of $\mathrm{CaP}$ crystals onto collagen fibrils. (b) Matrix vesiclemediated mineralization, which is based on the formation and release of intracellular matrix vesicles containing CaP crystals by the outer membranes of osteoblasts. ${ }^{68}$

engineering applications. The most relevant chemical groups will be addressed in separate subsections, which are further subcategorized as sections on classic polymer-ceramic nanocomposites versus composites prepared by means of wet chemical mineralization.

\section{Carboxyl groups}

Organic compounds containing carboxyl groups of high affinity for $\mathrm{Ca}^{2+}$ generally include full proteins, peptide se- quences, single amino acids, and $\mathrm{COOH}$ groups. ${ }^{106}$ These different categories will be described in detail in the following subsections.

Proteins. The affinity of certain proteins for HA can be exploited to regulate the nucleation, orientation, and growth of bone apatite under physiological conditions. ${ }^{108,109}$ The interactions of proteins with HA were first investigated in the 1950s using chromatography by Tiselius et al., ${ }^{110}$ who found that these interactions were mainly electrostatic. ${ }^{109}$

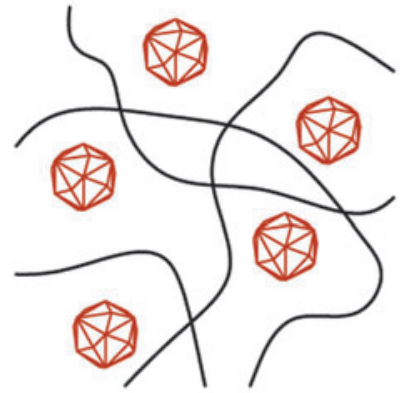

(i)

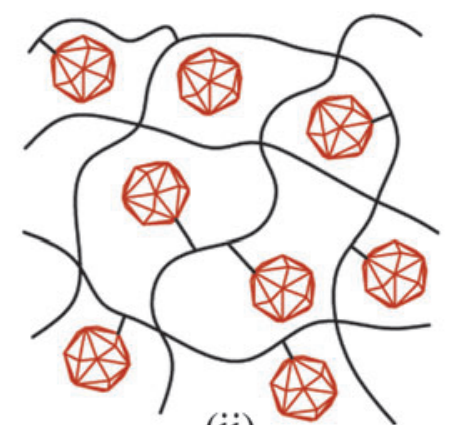

(ii)

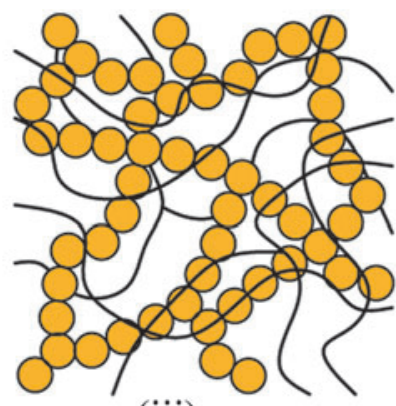

(iii)

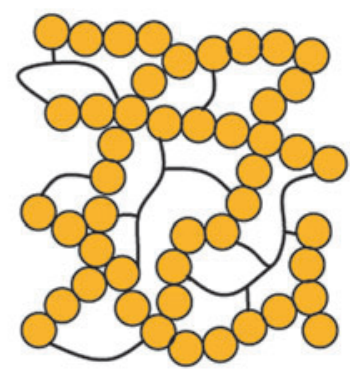

(iv)

FIG. 2. Different types of mutual arrangement of nanoparticles with polymer chains: (i) dispersed inorganic particles in the organic continuous phase (blend); (ii) pendant inorganic groups bonded to the polymer backbone; (iii) interpenetrating network of inorganic components and polymers; (iv) dual inorganic-organic hybrid polymers, where covalent bonds exist between the two phases. ${ }^{103,104}$ 


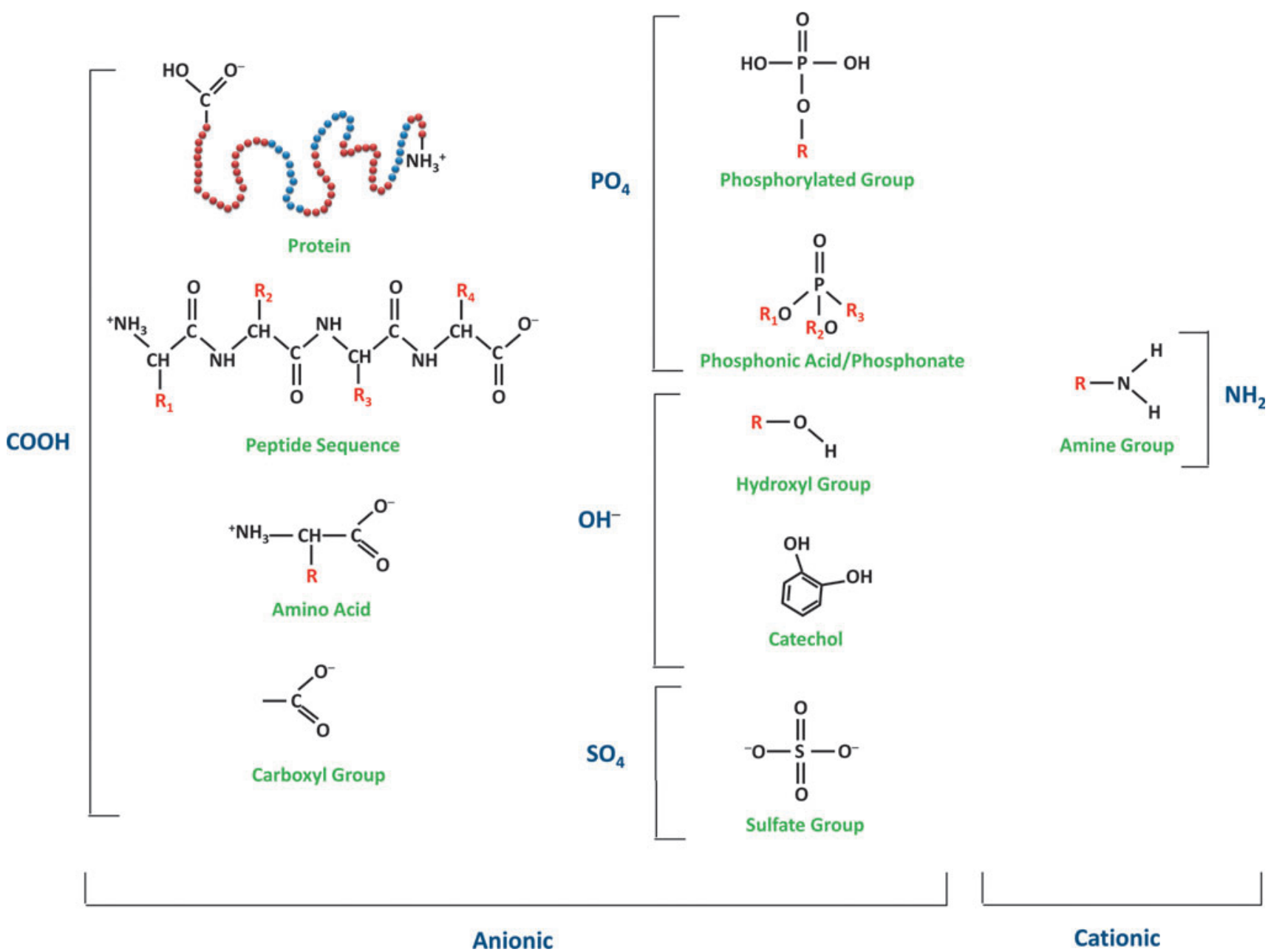

FIG. 3. Functional groups with high affinity for CaP.

Later, thorough investigations on HA binding of proteins with isoelectric points $(\mathrm{pI})$ ranging from 3.5 to 11.0 , basic proteins of high pI were suggested to bind HA mainly through nonspecific electrostatic interactions between $-\mathrm{NH}_{3}{ }^{+}$groups and anionic moieties on HA surface, whereas acidic proteins of low $\mathrm{pI}$ were found to bind mainly through complexation between $-\mathrm{COO}^{-}$and $\mathrm{Ca}^{2+}$ in HA. ${ }^{111-113}$ The ionic composition as well as the immediate environment affects the interactions of proteins with HA. The presence of $\mathrm{Ca}^{2+}$ in the medium improves the binding of acidic proteins to $\mathrm{HA}^{114}$ Besides the direct influence on HA binding, $\mathrm{Ca}^{2+}$ in solution is anticipated to enhance the HA binding efficiency by inducing an optimal configuration of protein $\alpha$ helices. ${ }^{115}$ The $\mathrm{PO}_{4}{ }^{3-}$ in solution inhibits the HA binding of acidic proteins, most likely through competitive binding of $\mathrm{PO}_{4}{ }^{3-}$ with $\mathrm{Ca}^{2+}$ on $\mathrm{HA}$. It was shown that a decrease in $\mathrm{pH}$ generally increases the HA binding in acidic proteins. ${ }^{109,116-118}$ Investigations on the chemical interactions between carboxylate groups in the amino acid residues of collagen and the positively charged $\mathrm{Ca}^{2+}$ of $\mathrm{HA}$ revealed that nucleation of HA crystals on collagen in a supersaturated SBF solution is strongly dependent on the carboxylate groups in collagen, which, in turn, depend on the charged functional groups present in collagen. ${ }^{119}$
Mineralized polymers: Kikuchi et al. ${ }^{16}$ reported that in nanocomposites synthesized through a simultaneous titration coprecipitation method [using $\mathrm{Ca}(\mathrm{OH})_{2}, \mathrm{H}_{3} \mathrm{PO}_{4}$, and porcine atelocollagen], collagen molecules stimulated the alignment of HA nanocrystals through interactions between carboxyl groups on collagen and $\mathrm{Ca}^{2+}$ on the HA crystal surface. Fourier transform infrared (FTIR) spectroscopy showed that the asymmetric stretching vibration of a dissociated carboxyl group $\mathrm{COO}^{-}$, observed at $1340 \mathrm{~cm}^{-1}$ for pure collagen, shifted to lower wave numbers in the composite, indicating that two equivalent $\mathrm{C}-\mathrm{O}$ 1.5-fold bonds in $-\mathrm{COO}^{-}$were weakened due to the formation of a new chemical bond between $\mathrm{Ca}^{2+}$ on the HA surface and $-\mathrm{COO}^{-}$ on collagen. The resulting composite showed a selforganized nanostructure similar to bone assembled through the chemical interaction between HA and collagen. The composite was resorbed by osteoclast-like cells and stimulated osteoblasts to form new bone in the adjacent area. ${ }^{16}$ Collagen in its denatured form, that is, gelatin, has also been used as an organic matrix for preparation of nanocomposites. $^{120-122}$ Carboxyl ions present in gelatin in HA-gelatin nanocomposites [prepared through a precipitation process using $\mathrm{Ca}(\mathrm{OH})_{2}$ and $\mathrm{H}_{3} \mathrm{PO}_{4}$ as precursors] can be active sites for coordination of $\mathrm{Ca}^{2+}$ to form ion complexes, which in 
turn interact with $\mathrm{PO}_{4}{ }^{3-}$. The observed increase in decomposition temperatures analyzed by differential thermal/ thermal gravimetric analysis (DT/TGA) suggests the formation of a primary chemical bond between HA and gelatin, which is further supported by FTIR analysis, confirming the induction of a red-shift of the $1339 \mathrm{~cm}^{-1}$ band of gelatin due to the chemical bonding between $\mathrm{Ca}^{2+}$ of HA and carboxyl ions of gelatin molecules. ${ }^{122}$

Chirila et al. ${ }^{123}$ postulated that complex artificial proteins can be synthesized, which either accelerate or decelerate mineralization, thereby offering new opportunities for modulation of composite properties. To this end, motif-programmed artificial proteins were covalently immobilized with mineralization-related activity onto the surface of a poly(2-hydroxyethyl methacrylate) (pHEMA) hydrogel, and the influence of assaying conditions upon the ability of three artificial proteins (two proteins incorporating nacrein repetitive motifs [PS382 and PS458] and one protein incorporating DMP1 motifs [PS64] $)^{124,125}$ to modulate calcification in vitro was investigated. A long-term calcification assay of 9 weeks showed that all proteins increased the uptake of calcium by the proteinmodified pHEMA hydrogels. For PS382 and PS458, this behavior was opposite to that displayed when the same proteins were tested in a free state by a rapid solution assay (based on a decrease taking place in the $\mathrm{pH}$ upon rapid addition of a solution of $\mathrm{CaCl}_{2}$ to a solution of $\mathrm{NaHCO}_{3}$ leading to the precipitation of $\left.\mathrm{CaCO}_{3}\right){ }^{126}$ Such a difference was attributed to a restricted mobility of the proteins due to immobilization. ${ }^{123}$

Mineralized polymers can also be synthesized through intrafibrillar mineralization of collagen by applying a polymerinduced liquid-precursor (PILP) mineralization process. In an in vitro model system, Gower and his coworkers ${ }^{66}$ used polyaspartate to mimic the acidic NCPs engaged in bone formation. It was shown that the anionic polypeptide sequesters ions to induce an $\mathrm{ACP}$ precursor, and it was hypothesized that the early-stage precursor was highly hydrated, enabling fluidic droplets to be drawn into the gaps and grooves of collagen fibrils by capillary action. In a related study, ${ }^{127}$ ALP was applied to provide a slow release of inorganic phosphate ions from a phosphate ester, mimicking the biochemical processes of ion regulation found in natural bone formation. Transmission electron microscopy (TEM) and selected area electron diffraction (SAED) showed that nanocrystals of HA were intrafibrillar and oriented along the collagen fibril axis within the collagen-HA composites. The precursor phase could achieve a good depth of penetration into dense collagen scaffolds, supporting the hypothesis that the polymer enters the collagen by means of capillary actions and not diffusive transport. A mineral coating was also reported on the surface of the collagen fibrils, which was thought to occur once the fibrils have become infiltrated with minerals, such that minerals proceed to build up on the exterior. Indeed, in natural bone formation, both intrafibrillar and extrafibrillar minerals are present. In this system, however, the mineral coating may have formed too rapidly, thus blocking subsequent intrafibrillar mineral penetration. ${ }^{127}$ Summarizing, it was shown that through further optimization (e.g., varying the polymer molecular weight), a very high degree of mineralization can be obtained, with compositions matching that of bone. ${ }^{128}$

Peptide sequences. Natural ECM biopolymers and proteins (such as collagen, laminin, fibronectin, and elastin) have been widely used for modification of synthetic polymeric biomaterial surfaces to modulate cell-substrate interactions. ${ }^{129}$ ECM proteins include signaling domains that usually comprise only few amino acids (short peptide sequences), and are the major interaction sites with cell surface receptors to facilitate cell adhesion. ${ }^{130-133}$ Nevertheless, degradation and purification of proteins can result into undesired side effects. ${ }^{134,135}$ Furthermore, even in the absence of protein degradation, conformational changes can compromise the biological efficacy of proteins. ${ }^{136-138}$ In comparison to full-length proteins, the use of short peptide sequences is advantageous as peptide sequences are simple, chemically well defined, biologically active, easy to synthesize, and simple to use for functionalization of macromers. ${ }^{139-144}$ As such, peptide functionalization allows for greater control over the conjugation chemistry using a wide variety of chemical approaches. Nonetheless, in comparison to full-length proteins, short peptide sequences have disadvantages such as their decreased receptor specificity, significantly weaker receptor affinity, and often reduced biological efficacy. ${ }^{129}$

Mineralized polymers: Itoh et al. ${ }^{145}$ treated HA surfaces with a $\mathrm{E}_{7} \mathrm{PRGDT}$ peptide of high affinity to $\mathrm{HA}^{146,147}$ owing to heptaglutamic acid sequence, and showed that attachment of osteoblastic cells and the expression of osteoblastic phenotypes, including mineralization, were enhanced by the peptide treatment. Inspired by the abundant presence of Glu residues in osteonectin, Sarvestani et al. ${ }^{148,149}$ investigated the calcium-binding capacity of an osteonectin-derived hexaglutamic acid sequence (Glu6) to enhance the interaction between HA nanoparticles and poly(lactide ethylene oxidefumarate) hydrogels as a nanocomposite for bone regeneration. To this end, acrylate-functionalized Glu6 peptides were used as linkers between inorganic and organic components of the composite. It was shown that the presence of Glu6 considerably improved the shear modulus of the composite due to increased ionic interactions between the peptide and HA nanocrystals $(\sim 100 \mathrm{~nm})$, whereas the same treatment applied for HA microparticles $(5 \mu \mathrm{m})^{149}$ did not show any significant improvement in the shear modulus. It was suggested that these findings can be used to develop advanced biomimetic composites for skeletal tissue regeneration. ${ }^{148,149}$

Culpepper et al. ${ }^{150}$ investigated the use of a HA binding domain, heptaglutamate (E7) rich in carboxyl groups, to improve the efficacy of coupling of the collagen mimetic peptide, DGEA (Asp-Gly-Glu-Ala), to HA-containing materials, and found that the E7 domain directed significantly more peptide to the surface of HA and enhanced peptide retention both in vitro and in vivo. It was shown that E7DGEA-coupled HA, compared to DGEA-HA, improved the adhesion and osteoblastic differentiation of mesenchymal stem cells, and also enhanced new bone formation and directed bone-implant contact on HA disks that were implanted in vivo. Furthermore, it was suggested that the E7 domain can perform as a general means for anchoring a wide variety of bone regenerative molecules to any type of HAcontaining material, for example, to the surface of allografts to reintroduce osteoinductive signals and potentially advance allograft treatments. ${ }^{150-152}$

Single amino acids. As mentioned before, single acidic amino acids can also be used to stimulate interaction with $\mathrm{Ca}^{2+}$. 
Mineralized polymers: Yang et al. ${ }^{153}$ investigated the effect of the presence of asparagine (Asn), glycine (Gly), and lysine (Lys) on HA crystallization, and showed that all amino acids accelerated HA nucleation, while the resulting crystals were smaller than those synthesized in the absence of amino acids. ${ }^{154}$ In a comparable approach, Palazzo et al. ${ }^{155}$ investigated the role of alanine (Ala), arginine (Arg), and aspartic acid (Asp) on nucleation, size, and morphology of calciumdeficient $\mathrm{HA}(\mathrm{CDHA})$ with a $\mathrm{Ca} / \mathrm{P}$ ratio of 1.53 prepared at $\mathrm{pH}$ 10. All particles formed in the presence of amino acids showed a thin amorphous layer on the surface, which most likely consisted of the respective amino acid. It was argued that alanine binds weakly to the surface of the CDHA plates through the interaction between the amino acid carboxylate and calcium sites on the particle surface. Different from alanine, which contains only a C-terminal carboxylate, asparagine may form a cooperative link with the same or a neighboring calcium surface site engaging the carboxylate side chain as well as the C-terminal carboxylate. Arginine binds to the phosphate group using its guanidinium side chain, although when the C-terminal carboxylate is already bound to a calcium site. ${ }^{154,155}$ Such a model is remarkable due to a simultaneous binding to both the anionic and cationic surface sites, which proposes a more specific approach of tailoring $\mathrm{CaP}$ morphologies and crystal phases than the currently possible approaches with simple anionic or cationic additives. ${ }^{154}$

Boanini et al. ${ }^{156}$ prepared nanocomposites of HA-aspartic acid and HA-glutamic acid through a direct synthesis of HA nanocrystals in the presence of different amounts of amino acids in solution. It was discussed that incorporation of Asp and Glu into HA crystals decreases the coherent length of the perfect crystalline domains along certain planes of apatite crystals, which results in a specific interaction of the amino acids with the HA structure. FTIR spectra showed a small shift of the carboxylic stretching band to lower wave numbers, consistent with an enhancement of the $\mathrm{C}-\mathrm{O}$ bond length due to interaction with the apatitic phase. The relative amount of Asp incorporation into HA nanocrystals in their study was greater compared with Glu, suggesting a greater affinity of Asp for HA. Furthermore, it was revealed that the presence of amino acids stimulated the growth of osteoblastlike cells (MG63) in vitro and improved their differentiation, compared to HA without the presence of amino acids. ${ }^{156}$

Furuichi et al. ${ }^{157}$ prepared hierarchically organized structures of nanocrystalline HA through periodic precipitation in a nonequilibrium reaction system with diffusion of $\mathrm{Ca}^{2+}$ into a poly(acrylic acid) (PAA) matrix, which contains one carboxyl group per monomer. ${ }^{158}$ The diffusion of $\mathrm{Ca}^{2+}$ into the carboxyl-rich PAA hydrogel containing $\mathrm{PO}_{4}{ }^{3-}$ stimulated the calcification of the hydrogel matrix and gave rise to a hierarchically structured nanocomposite that resembled bone. ${ }^{157,159}$ To investigate the effect of organic molecules on the crystal growth of $\mathrm{CaP}$, gelatin was added to replace acrylic acid in the precursor solution (up to $40 \mathrm{wt} \%$ ), whereas equal amounts of aspartic acid and glutamic acid were added to study the influence of single amino acids in gelatin molecules on the morphology of mineralization. The substitution of Asp and Glu for $40 \mathrm{wt} \%$ PAA gel showed a similar influence on the morphology at nanoscopic and microscopic scales as compared to the polymer gelatin, since both amino acids and gelatin macromolecules stimulated the formation of HA and its one-dimensional arrangement in the fibrous morphology of the synthesized hydrogel. It was suggested that the laminated HA-polymer composites could have potential for applications in tissue engineering due to the similarity in mechanical properties to bone tissue. The hierarchical porous HA architectures could be useful as adsorbents and as scaffolds for tissue engineering. ${ }^{157}$

Single carboxyl groups. Similar to exploiting carboxyl groups as present in larger entities such as proteins, peptide sequences, and amino acids, single carboxyl groups can also be used for increasing the binding affinity of macromolecules to CaP. Compared to proteins or peptides, the use of single carboxyl groups offers improved control over the presentation of calcium-binding groups owing to the adjustable density of $\mathrm{COOH}$ groups and the absence of other functional groups, which might interfere with the desired $\mathrm{Ca}^{2+}-\mathrm{COOH}$ interaction.

Mineralized polymers: Citrate molecules are known to be abundantly present at the interface between collagen and apatite crystals in bone, ${ }^{160}$ and have the ability to strongly bind to apatite and cover the surface with a density of one citrate molecule per $4 \mathrm{~nm}^{2} .{ }^{161}$ This density is approximately one-sixth of the available area of the apatite surface. ${ }^{160,161}$ Citrate molecules in bone account for $\sim 80 \%$ of the total weight of citrate as present in the human body, thereby being the main source of carboxylate groups in bone. As such, carboxylate groups appear to have a pivotal role in regulating the process of apatite nucleation. ${ }^{161}$ Inspired by the in vitro studies on the bonding between citrate anions and bone mineral, ${ }^{162,163} \mathrm{Hu}$ et al. ${ }^{161}$ proposed that the addition of citrate (containing three carboxyl groups per molecule) ${ }^{164}$ in the bottom-up synthesis of self-assembled pluronic polymerHA nanocomposites allows for molecular control over the growth of the apatite crystal size, comparable to mineralization in native bone. It was expected that the biocompatibility of biosynthetic materials can be improved through incorporation of citrate within the nanocomposites to produce similarly structured HA nanocrystals as in bone apatite. Citrate molecules were shown to be capable to stabilize extremely small HA crystals of $2 \mathrm{~nm}$ size, while the HA crystal size could be fine-tuned at nanoscale by changing the citrate concentration. ${ }^{161}$ It is also known that specific adsorption of citrate anions onto $\mathrm{CaP}$ nanocrystals in $\mathrm{CaP}$-gelatin nanocomposites results in negatively charged $\mathrm{CaP}$ particles and accordingly enhances repulsive interparticle forces that are able to stabilize $\mathrm{CaP}$ suspensions and reduce agglomeration and sedimentation of apatitic nanoparticles in lyophilized gelatin matrices. ${ }^{165}$

Phadke et al. ${ }^{166}$ synthesized bone-like composites by using synthetic hydrogels, including pendant side chains functionalized with $\mathrm{COOH}$ groups as templates for mineralization. The influence of matrix hydrophobicity on the nucleation of apatite-like phases on a polymeric substrate was investigated by utilizing poly(ethylene glycol) (PEG) hydrogels modified with anionic pendant side chains of variable length $\left(\mathrm{CH}_{2}=\right.$ $\mathrm{CHCONH}\left(\mathrm{CH}_{2}\right)_{n} \mathrm{COOH}$, where $n=1,3,5$, and 7). ${ }^{167,168}$ The pendant side chains contained $\mathrm{Ca}^{2+}$-binding carboxyl groups, which provided nucleation sites for the formation of crystalline $\mathrm{CaP}$. Changing the number of $\mathrm{CH}_{2}$ groups allowed for systematic modification of matrix hydrophobicity without varying the terminal functional group. Binding of 
$\mathrm{Ca}^{2+}$ to functional groups of the matrix resulted in nucleation of mineral phases. ${ }^{166}$

Traditionally, the mineralizing capacity of acrylated polymers has been extensively investigated in view of the abundant presence of carboxyl groups. The pHEMA hydrogel scaffold, for instance, has been used to expose carboxylate groups on the surface of crosslinked pHEMA, thereby promoting nucleation and growth of $\mathrm{CaP}$ crystals on the surface as well as in the hydrogel interior. ${ }^{169}$ The influence of polyacrylate on the biomimetic growth of HA on gelatin films was studied by Bigi et al., ${ }^{170}$ since polyacrylate is a carboxylate-rich polyelectrolyte, which would resemble the presence of the acidic macromolecules in the ECM of bone. The results suggested that the combined effect of stretching and the presence of carboxylate groups promoted the nucleation and ordered growth of HA crystals inside gelatin. ${ }^{170}$ Besides synthetic carboxyl-rich polymers such as polyacrylates, carboxyl groups as present in natural biopolymers such as alginate can also be used to increase the interaction with calcium ions. By chemically crosslinking poly(propylene glycol) monomethacrylate, PEG monomethacrylate, and methacrylic alginate, Cha et al. ${ }^{171}$ synthesized nanoporous and microporous hydrogels, which were incubated in modified SBF to induce mineralization of the gel matrices. It was demonstrated that carboxylic groups in alginate induced the deposition of $\mathrm{Ca}^{2+}$ in both hydrogel types, resulting in the accumulation of mineral ions. ${ }^{171}$

\section{Phosphate and phosphonate groups}

Besides carboxyl groups, phosphate and phosphonate groups can also be used to increase the affinity of polymers to mineral fillers.

Phosphate groups. Mineralized polymers: Suzuki et al. ${ }^{172}$ prepared block copolymers consisting of poly (monoacryloxyethyl phosphate) (PMAEP) or poly(2(methacryloyloxy)-ethyl phosphate) (PMOEP) and poly(2(acetoacetoxy)ethyl methacrylate), and immobilized them on aminated slides. It was revealed that both soluble PMAEP polymers and crosslinked PMOEP gels facilitated the formation of crystalline CaP deposition. ${ }^{172}$ Using a comparable chemistry, Chirila et al. ${ }^{173}$ introduced phosphate groups into carboxylate-rich pHEMA hydrogels by copolymerization with mono(2-acryloyloxyethyl) phosphate or mono(2methacryloyloxyethyl) phosphate. It was shown that the introduction of these phosphate groups decreased the calcification capacity of pHEMA hydrogels, stressing that the mere presence of phosphate groups is not a guarantee for increased mineralization of polymers. ${ }^{173}$

Kim et al. ${ }^{174}$ used a urea-mediated solution precipitation technique to precipitate $\mathrm{CaP}$ crystals on the surface and interior of a PEG-based hydrogel. The hydrogel was synthesized by radical crosslinking polymerization of PEGfumarate in the presence of ethylene glycol methacrylate phosphate as an attempt to use phosphate groups to stimulate the formation of apatitic crystalline platelets. ${ }^{159}$ To provide the apatite-nucleating function of phosphorylated proteins in the collagen-associated ECM, phosphoryl anionic functionality was introduced in the PEG-based hydrogels during crossliking polymerization. ${ }^{174}$ Since ester groups and amide groups in hydrogels were not expected to nucleate apatite crystals, ${ }^{175}$ the observed apatite formation on the hydrogels was ascribed to the presence of acidic phosphorylated groups. In vitro cell experiments revealed that the cell adhesion/proliferation on the mineralized hydrogel was more pronounced than on the pure polymer hydrogel. ${ }^{174}$

Studying the influence of phosphorylation and sequence scrambling on peptide adsorption to four different apatites (bone-like mineral, and three types of apatite containing carbonate contents of $0 \%, 5.6 \%$, and $10.5 \%$ ) has shown that phosphorylation of the VTKHLNQISQSY peptide (VTK peptide) can result in a 10-fold increase in peptide adsorption (in comparison to the nonphosphorylated peptide) to bonelike mineral, and a twofold increase in adsorption to carbonated apatite; however, no influence of phosphorylation on peptide affinity to pure HA (without carbonate) was observed. Computational modeling of peptide-mineral interactions also revealed a favorable change in binding energy upon phosphorylation, which was unchanged by scrambling. In summary, phosphorylation of serine residues could enhance peptide specificity for bone-like mineral. ${ }^{176}$ Sailaja et al. ${ }^{177}$ evaluated the in vitro functionality of phosphorylated pHEMA-co-methyl methacrylate [poly(HEMA-co-MMA)] to induce bioinspired mineralization of the $\mathrm{CaP}$ phase, and revealed that the primary nucleation of $\mathrm{CaP}$ on the surface of the phosphorylated copolymer occurred within 3 days of immersion in 1.5 SBF and the degree of mineralization was proportional to the methacrylate content in the copolymer. The concentration of calcium in the coating increased with increasing the HEMA content in the copolymer. Consequently, the surface phosphorylated poly(HEMA-co-MMA) could be proposed as a potential substrate capable of inducing in vitro mineralization of HA. ${ }^{177}$ The possibility of using sodium trimetaphosphate (STMP), a chemical phosphorylating reagent, as a functional analog of matrix phosphoproteins for biomimetic remineralization of resin-bonded dentin has also been studied. Equilibrium adsorption and desorption studies of STMP were carried out using demineralized dentin powder (DDP), and an analysis of saturation binding curves confirmed the presence of irreversible phosphate-binding sites on the surface of DDP. FTIR spectroscopy provided further evidence for chemical interactions between trimetaphosphate and dentin powder, with enhancement in peak intensities of the $\mathrm{P}=\mathrm{O}$ and $\mathrm{P}-\mathrm{O}-\mathrm{C}$ stretching modes. These peaks returned to their initial intensities after ALP treatment. ${ }^{178}$

Phosphonate groups. Mineralized polymers: By crosslinking collagen with carbodiimide (EDC), Gu et al. ${ }^{179}$ could enhance the sieving property of collagen, enabling polyvinylphosphonic acid (PVPA) to be immobilized within collagen. A concentration range for immobilized PVPA to template intrafibrillar apatite deposition was set up and validated using a single-layer reconstituted type I collagen mineralization model. In the presence of a PAA-containing mineralization medium, optimal intrafibrillar mineralization of the EDC-crosslinked collagen was obtained using 500 and $1000 \mu \mathrm{g} / \mathrm{mL}$ PVPA. The mineralized fibrils showed a hierarchical order of intrafibrillar mineral infiltration, as noticeable by the appearance of electron-dense periodicity within unstained fibrils. It was suggested that appreciating the basic processes in intrafibrillar mineralization of reconstituted collagen could create opportunities for the design of tissue 
engineering materials for hard tissue repair and regeneration. ${ }^{179}$

Bisphosphonates (BPs) are synthetic analogues for pyrophosphates that display a remarkable affinity to bone mineral. This property is mediated through $(\mathrm{HO})_{2}-\mathrm{OP}-\mathrm{C}-$ $\mathrm{PO}-(\mathrm{OH})_{2}$ moieties that act as chelators of $\mathrm{Ca}^{2+}$ cations. Interestingly, the distance between deprotonated oxygens is 2.9-3.1 $\AA$, which is in the same range as the oxygen ions in $\mathrm{HA}^{180,181}$ and is therefore likely the optimum distance for the chelation of $\mathrm{Ca}^{2+}$ ions in HA. ${ }^{109}$ BPs can be linked to organic compounds using straightforward chemical approaches, ${ }^{109}$ which render BPs ideal for targeted delivery purposes or alternatively as $\mathrm{CaP}$-binding moieties to serve as a strong linkage between organic and inorganic phases in next generation nanocomposites. Yang et al. ${ }^{182}$ synthesized an injectable in situ forming hybrid hydrogel by preparing a hyaluronic acid (HAc) derivative, dually functionalized with crosslinkable hydrazide groups and BP ligands (HAc-hy$\mathrm{BP})$, and subsequent mixing of the HAc-hy-BP solution and the $\mathrm{Ca}^{2+}$ ions containing a solution of aldehyde-derivatized $\mathrm{HAc}$ (HAc-al). It was shown that the conjugation of BP to the hydrogel matrix can stimulate an efficient and fast mineralization of the matrix. The mineralization was promoted by the strong interaction between $\mathrm{BP}$ residues and $\mathrm{Ca}^{2+}$ ions that serve as nanometer-sized nucleation sites for further $\mathrm{CaP}$ deposition within the HAc hydrogel. ${ }^{182}$

Classic nanocomposites: BPs can also be used to overcome the inertness of certain compounds, such as PEG-modified polyethyleneimine (PEI). Despite the significant potential of PEI to interact with charged surfaces ${ }^{183,184}$ and its high affinity to bone mineral HA, ${ }^{185}$ Wang et al. ${ }^{186,187}$ noticed that PEG-modified PEI significantly loses its inherent ability of binding to HA as a function of PEG substitution degree. In a later study, ${ }^{188}$ this lack of HA affinity was compensated through further conjugation with BP. In a related study, ${ }^{189}$ a conjugate of distearoylphosphoethanolamine (DSPE)-PEG with 2-(3-mercaptopropylsulfanyl)-ethyl-1,1-bisphosphonic acid (SH-BP) was also synthesized and incorporated into micelles and liposomes to produce mineral-binding nanocarriers for therapeutic agents, and the in vitro affinity of the micellar and liposomal formulations to HA was investigated. It was shown that all SH-BP-incorporated nanocarriers exhibited a stronger HA affinity compared to their counterparts without SH-BP. Furthermore, the SH-BP-decorated liposomes showed a strong binding to a collagen-HA composite scaffold in vitro, and gave increased retention in the collagen-HA scaffolds after subcutaneous implantation in vivo. ${ }^{189}$ Boanini et al. ${ }^{190}$ successfully synthesized HAalendronate composites at different BP contents up to about $7 \mathrm{wt} \%$, and showed that BPs not only inhibit bone dissolution, but can also influence the deposition of the bone mineral phase. It was suggested that alendronate-containing nanocrystals offer a relevant tool in view of the possible applications of these composites as biomaterials for hard tissue repair. ${ }^{190}$

\section{Hydroxyl groups}

Hydroxyl groups (including hydroxyl-containing groups such as catechols or fenols) are anionic functional groups with high affinity for $\mathrm{Ca}^{2+}$. For instance, the affinity of BPs for $\mathrm{Ca}^{2+}$ is greater if the side chain contains a hydroxyl group, such as in etidronate, ${ }^{191}$ because this allows tridentate coordination to $\mathrm{Ca}^{2+} \cdot{ }^{192}$

Mineralized polymers: Hutchens et al. ${ }^{193}$ synthesized a nanocomposite comprised CDHA biomimetically deposited in a bacterial cellulose hydrogel. ${ }^{159} \mathrm{CDHA}$ was formed in bacterial cellulose by alternate incubation with calcium and phosphate solutions. FTIR spectroscopy showed that CDHA is bonding with the bacterial cellulose through hydroxyl groups of the cellulose. It was stated that cellulose hydroxyl groups possessed a strong negative dipole that could chelate free $\mathrm{Ca}^{2+}$ in the $\mathrm{CaCl}_{2}$ solution and form a coordinated bond, after which $\mathrm{PO}_{4}{ }^{3-}$ could bond with the cellulose-associated calcium to form CaP. The synthesis of the composite mimicked the natural biomineralization of bone signifying that bacterial cellulose can be applied as a template for biomimetic apatite formation. The discussed composite offers a potential use as an orthopedic biomaterial. ${ }^{193}$

The apatite-forming ability of polyamide (containing carboxyl groups) modified with different amounts of silanol groups has also been studied. ${ }^{194}$ It was found that the rate of apatite formation was enhanced with the increasing content of silanol groups in the polyamide films, which was attributed to the enhancement of dipole interactions, that is, the lower electronegativity of silicon compared to carbon enabled calcium ions to access near lone electron pairs of oxygen atoms in silanol groups in a dipole interaction. ${ }^{194}$ Ryu et al. ${ }^{195}$ showed that catechol groups as present in polydopamine layers were able to nucleate HA by concentrating $\mathrm{Ca}^{2+}$ at the interface. As deposition of polydopamine layers is essentially a simple dip coating procedure at alkaline conditions, this procedure would be suitable to mineralize a wide variety of biomaterials. ${ }^{195}$ Douglas et al., ${ }^{196}$ for instance, observed that enzymatic mineralization of gellan gum hydrogels was improved by incorporation of polydopamine.

\section{Sulfate groups}

In addition to the above-mentioned anionic functional groups, sulfate ions have been found to show affinity for $\mathrm{CaP}$ as well.

Classic nanocomposites: In view of the mineral-binding affinity of sulfate groups, Chang et al. ${ }^{197}$ prepared a HAgelatin nanocomposite in which the gelatin matrix was modified by the introduction of chondroitin sulfate (ChS) aiming to obtain a strongly organized composite body. It was shown that $\mathrm{CaP}$ was strongly bound to the ChSmodified gelatin macromolecules, and the matrix of the gelatin-ChS molecules was mineralized by HA nanocrystallites. It was claimed that the HA-gelatin-ChS nanocomposites were formed by the interaction between the critically small size of HA crystallites and the interpenetrating network structure of the gelatin-ChS complex. A small amount of ChS significantly enhanced the organic-organic interaction between gelatin and ChS, indicating the formation of the interpenetrating network structure of the gelatinChS complex, which chemically interacted with the calcium and phosphate ions to form HA. ${ }^{197}$

\section{Conclusions}

This review highlighted the inorganic-organic interactions in the ECM of bone as well as synthetic nanocomposites 
whose design was inspired by the nanostructure of bone tissue. Biomacromolecules functionalized to induce mineralization in a polymer matrix were also addressed, due to their potential for interacting with $\mathrm{CaP}$ nanoparticles. Anionic (and/or cationic) functional groups of the organic matrix with high affinity for binding either calcium or phosphate ions of bone apatite are responsible for these interactions. Anionic functional groups-more specifically, carboxylcontaining and calcium-binding moieties, including proteins, peptide sequences, single amino acids, and $\mathrm{COOH}$ groupsare the most extensively investigated chemical groups that can be instrumental to improve the interaction between inorganic and organic phases in synthetic nanocomposites for bone regeneration. However, other anionic groups such as phosphates, phosphonates, sulfates, and hydroxyl groups are also gaining interest.

\section{Acknowledgments}

The authors are grateful for the funding support from NIRM, the Netherlands Institute for Regenerative Medicine.

\section{Disclosure Statement}

No competing financial interests exist.

\section{References}

1. Chan, C.K., Kumar, T.S., Liao, S., Murugan, R., Ngiam, M., and Ramakrishnan, S. Biomimetic nanocomposites for bone graft applications. Nanomedicine (Lond) 1, 177, 2006.

2. Spicer, P.P., Kretlow, J.D., Young, S., Jansen, J.A., Kasper, F.K., and Mikos, A.G. Evaluation of bone regeneration using the rat critical size calvarial defect. Nat Protoc 7, 1918, 2012.

3. Kretlow, J.D., and Mikos, A.G. Review: Mineralization of synthetic polymer scaffolds for bone tissue engineering. Tissue Eng 13, 927, 2007.

4. Porter, J.R., Ruckh, T.T., and Popat, K.C. Bone tissue engineering: a review in bone biomimetics and drug delivery strategies. Biotechnol Prog 25, 1539, 2009.

5. Silber, J.S., Anderson, D.G., Daffner, S.D., Brislin, B.T., Leland, J.M., Hilibrand, A.S., Vaccaro, A.R., and Albert, T.J. Donor site morbidity after anterior iliac crest bone harvest for single-level anterior cervical discectomy and fusion. Spine (Phila Pa 1976) 28, 134, 2003.

6. Rogers, S.N., Lakshmiah, S.R., Narayan, B., Lowe, D., Brownson, P., Brown, J.S., and Vaughan, E.D. A comparison of the long-term morbidity following deep circumflex iliac and fibula free flaps for reconstruction following head and neck cancer. Plast Reconstr Surg 112, 1517, 2003.

7. Niinomi, M. Metallic biomaterials. J Artif Organs 11, 105, 2008.

8. Habraken, W.J.E.M., Wolke, J.G.C., and Jansen, J.A. Ceramic composites as matrices and scaffolds for drug delivery in tissue engineering. Adv Drug Deliv Rev 59, 234, 2007.

9. Kohane, D.S., and Langer, R. Polymeric biomaterials in tissue engineering. Pediatr Res 63, 487, 2008.

10. Staiger, M.P., Pietak, A.M., Huadmai, J., and Dias, G. Magnesium and its alloys as orthopedic biomaterials: A review. Biomaterials 27, 1728, 2006.

11. Kannan, M.B., and Raman, R.K. In vitro degradation and mechanical integrity of calcium-containing magnesium alloys in modified-simulated body fluid. Biomaterials 29, 2306, 2008.
12. Wang, H., and Shi, Z. In vitro biodegradation behavior of magnesium and magnesium alloy. J Biomed Mater Res B Appl Biomater 98B, 203, 2011.

13. Ebramzadeh, E., Normand, P.L., Sangiorgio, S.N., Llinás, A., Gruen, T.A., McKellop, H.A., and Sarmiento, A. Longterm radiographic changes in cemented total hip arthroplasty with six designs of femoral components. Biomaterials 24, 3351, 2003.

14. Antunes, R.A., and de Oliveira, M.C. Corrosion fatigue of biomedical metallic alloys: Mechanisms and mitigation. Acta Biomater 8, 937, 2012.

15. Yamamoto, A., Honma, R., and Sumita, M. Cytotoxycity of metal salts and its compound effects. In: Ikada, Y., and Zhang, X., eds. Biomedical Materials Research in the Far East (II). Kyoto: Kobunshi Kankokai, Inc., 1996, pp. 89-90.

16. Kikuchi, M., Itoh, S., Ichinose, S., Shinomiya, K., and Tanaka, J. Self-organization mechanism in a bone-like hydroxyapatite/collagen nanocomposite synthesized in vitro and its biological reaction in vivo. Biomaterials 22, 1705, 2001.

17. Wong, J.Y., and Bronzino, J.D. Biomaterials. New York: CRC Press, 2007.

18. Rezwan, K., Chen, Q.Z., Blaker, J.J., and Boccaccini, A.R. Biodegradable and bioactive porous polymer/inorganic composite scaffolds for bone tissue engineering. Biomaterials 27, 3413, 2006.

19. Choi, J., Harcup, J., Yee, A.F., Zhu, Q., and Laine, R.M. Organic/inorganic hybrid composites from cubic silsesquioxanes. J Am Chem Soc 123, 11420, 2001.

20. Hsu, F.Y., Chueh, S.C., and Wang, Y.J. Microspheres of hydroxyapatite/reconstituted collagen as supports for osteoblast cell growth. Biomaterials 20, 1931, 1999.

21. Sivakumar, M., and Panduranga Rao, K. Preparation, characterization and in vitro release of gentamicin from coralline hydroxyapatite-gelatin composite microspheres. Biomaterials 23, 3175, 2002.

22. Cushnie, E.K., Khan, Y.M., and Laurencin, C.T. Amorphous hydroxyapatite-sintered polymeric scaffolds for bone tissue regeneration: Physical characterization studies. J Biomed Mater Res A 84, 54, 2008.

23. Chesnutt, B.M., Yuan, Y., Buddington, K., Haggard, W.O., and Bumgardner, J.D. Composite chitosan/nano-hydroxyapatite scaffolds induce osteocalcin production by osteoblasts in vitro and support bone formation in vivo. Tissue Eng Part A 15, 2571, 2009.

24. Lv, Q., Nair, L., and Laurencin, C.T. Fabrication, characterization, and in vitro evaluation of poly(lactic acid glycolic acid)/nano-hydroxyapatite composite microsphere-based scaffolds for bone tissue engineering in rotating bioreactors. J Biomed Mater Res A 91, 679, 2009.

25. Leeuwenburgh, S.C., Jo, J., Wang, H., Yamamoto, M., Jansen, J.A., and Tabata, Y. Mineralization, biodegradation, and drug release behavior of gelatin/apatite composite microspheres for bone regeneration. Biomacromolecules 11, 2653, 2010.

26. Wang, H., Leeuwenburgh, S.C.G., Li, Y., and Jansen, J.A. The use of micro- and nanospheres as functional components for bone tissue regeneration. Tissue Eng Part B Rev 18, 24, 2011.

27. Wang, Y., Azaïs, T., Robin, M., Vallée, A., Catania, C., Legriel, P., Pehau-Arnaudet, G., Babonneau, F., GiraudGuille, M.M., and Nassif, N. The predominant role of collagen in the nucleation, growth, structure and orientation of bone apatite. Nat Mater 11, 724, 2012. 
28. Matthews, F.L., and Rawlings, R.D. Composite Materials: Engineering and Science. London: Chapman \& Hall, 1994.

29. Morgan, E.F., Barnes, G.L., and Einhorn, T.A. The bone organ system: form and function. In: Marcus, R., Feldman, D., Nelson, D., and Rosen, C.J., eds. Fundamentals of Osteoporosis. San Diego, CA: Elsevier Academic Press, 2008, pp. 1-25.

30. Labat-Robert, J., Bihari-Varga, M., and Robert, L. Extracellular matrix. FEBS Lett 268, 386, 1990.

31. Schönherr, E., and Hausser, H.J. Extracellular matrix and cytokines: a functional unit. Dev Immunol 7, 89, 2000.

32. Rosso, F., Giordano, A., Barbarisi, M., and Barbarisi, A. From cell-ECM interactions to tissue engineering. J Cell Physiol 199, 174, 2004.

33. Pradhan, S., and Farach-Carson, M.C. Mining the extracellular matrix for tissue engineering applications. Regen Med 5, 961, 2010.

34. Fujisawa, R., and Tamura, M. Acidic bone matrix proteins and their roles in calcification. Front Biosci 17, 1891, 2012.

35. Edwards, G.M., Wilford, F.H., Liu, X., Hennighausen, L., Djiane, J., and Streuli, C.H. Regulation of mammary differentiation by extracellular matrix involves protein-tyrosine phosphatases. J Biol Chem 273, 9495, 1998.

36. Palmer, L.C., Newcomb, C.J., Kaltz, S.R., Spoerke, E.D., and Stupp, S.I. Biomimetic systems for hydroxyapatite mineralization inspired by bone and enamel. Chem Rev 108, 4754, 2008.

37. Beniash, E. Biominerals-hierarchical nanocomposites: the example of bone. Wiley Interdiscip Rev Nanomed Nanobiotechnol 3, 47, 2011.

38. Glimcher, M.J. Mechanism of calcification: role of collagen fibrils and collagen-phosphoprotein complexes in vitro and in vivo. Anat Rec 224, 139, 1989.

39. Nudelman, F., Pieterse, K., George, A., Bomans, P.H., Friedrich, H., Brylka, L.J., Hilbers, P.A., de With, G., and Sommerdijk, N.A. The role of collagen in bone apatite formation in the presence of hydroxyapatite nucleation inhibitors. Nat Mater 9, 1004, 2010.

40. Landis, W.J., Silver, F.H., and Freeman, J.W. Collagen as a scaffold for biomimetic mineralization of vertebrate tissues. J Mater Chem 16, 1495, 2006.

41. Cölfen, H. Biomineralization: a crystal-clear view. Nat Mater 9, 960, 2010

42. Dai, L., Qi, Y.P., Niu, L.N., Liu, Y., Pucci, C.R., Looney, S.W., Ling, J.Q., Pashley, D.H., and Tay, F.R. Inorganic-organic nanocomposite assembly using collagen as a template and sodium tripolyphosphate as a biomimetic analog of matrix phosphoprotein. Cryst Growth Des 11, 3504, 2011.

43. Oldberg, A., Franzén, A., and Heinegård, D. The primary structure of a cell-binding bone sialoprotein. J Biol Chem 263, 19430, 1988.

44. Hunter, G.K., and Goldberg, H.A. Nucleation of hydroxyapatite by bone sialoprotein. Proc Natl Acad Sci U S A 90, 8562, 1993.

45. Hunter, G.K., and Goldberg, H.A. Modulation of crystal formation by bone phosphoproteins: role of glutamic acidrich sequences in the nucleation of hydroxyapatite by bone sialoprotein. Biochem J 302 (Pt 1), 175, 1994.

46. Ganss, B., Kim, R.H., and Sodek, J. Bone sialoprotein. Crit Rev Oral Biol Med 10, 79, 1999.

47. Tye, C.E., Rattray, K.R., Warner, K.J., Gordon, J.A., Sodek, J., Hunter, G.K., and Goldberg, H.A. Delineation of the hydroxyapatite-nucleating domains of bone sialoprotein. J Biol Chem 278, 7949, 2003.
48. Chen, J., Shapiro, H.S., and Sodek, J. Developmental expression of bone sialoprotein mrna in rat mineralized connective tissues. J Bone Miner Res 7, 987, 2009.

49. Mazzali, M., Kipari, T., Ophascharoensuk, V., Wesson, J.A., Johnson, R., and Hughes, J. Osteopontin-a molecule for all seasons. QJM 95, 3, 2002.

50. Christensen, B., Petersen, T.E., and Sørensen, E.S. Posttranslational modification and proteolytic processing of urinary osteopontin. Biochem J 411, 53, 2008.

51. Gericke, A., Qin, C., Spevak, L., Fujimoto, Y., Butler, W.T., Sørensen, E.S., and Boskey, A.L. Importance of phosphorylation for osteopontin regulation of biomineralization. Calcif Tissue Int 77, 45, 2005.

52. Oldberg, A., Franzén, A., and Heinegård, D. Cloning and sequence analysis of rat bone sialoprotein (osteopontin) cDNA reveals an Arg-Gly-Asp cell-binding sequence. Proc Natl Acad Sci U S A 83, 8819, 1986.

53. Craig, A.M., Smith, J.H., and Denhardt, D.T. Osteopontin, a transformation-associated cell adhesion phosphoprotein, is induced by 12-O-tetradecanoylphorbol 13-acetate in mouse epidermis. J Biol Chem 264, 9682, 1989.

54. Fantner, G.E., Hassenkam, T., Kindt, J.H., Weaver, J.C., Birkedal, H., Pechenik, L., Cutroni, J.A., Cidade, G.A., Stucky, G.D., Morse, D.E., and Hansma, P.K. Sacrificial bonds and hidden length dissipate energy as mineralized fibrils separate during bone fracture. Nat Mater 4, 612, 2005.

55. Fantner, G.E., Adams, J., Turner, P., Thurner, P.J., Fisher, L.W., and Hansma, P.K. Nanoscale ion mediated networks in bone: osteopontin can repeatedly dissipate large amounts of energy. Nano Lett 7, 2491, 2007.

56. Thurner, P.J., Lam, S., Weaver, J.C., Morse, D.E., and Hansma, P.K. Localization of phosphorylated serine, osteopontin, and bone sialoprotein on bone fracture surfaces. J Adhes 85, 526, 2009.

57. Qin, C., Baba, O., and Butler, W. Post-translational modifications of sibling proteins and their roles in osteogenesis and dentinogenesis. Crit Rev Oral Biol Med 15, 126, 2004.

58. Canalis, E., and Lian, J.B. Effects of bone associated growth factors on DNA, collagen and osteocalcin synthesis in cultured fetal rat calvariae. Bone 9, 243, 1988.

59. Boivin, G., Morel, G., Lian, J.B., Anthoine-Terrier, C., Dubois, P.M., and Meunier, P.J. Localization of endogenous osteocalcin in neonatal rat bone and its absence in articular cartilage: effect of warfarin treatment. Virchows Arch A Pathol Anat Histopathol 417, 505, 1990.

60. Weinreb, M., Shinar, D., and Rodan, G.A. Different pattern of alkaline phosphatase, osteopontin, and osteocalcin expression in developing rat bone visualized by in situ hybridization. J Bone Miner Res 5, 831, 1990.

61. Ducy, P., Desbois, C., Boyce, B., Pinero, G., Story, B., Dunstan, C., Smith, E., Bonadio, J., Goldstein, S., Gundberg, C., Bradley, A., and Karsenty, G. Increased bone formation in osteocalcin-deficient mice. Nature 382, 448, 1996.

62. Ingram, R.T., Park, Y.K., Clarke, B.L., and Fitzpatrick, L.A. Age- and gender-related changes in the distribution of osteocalcin in the extracellular matrix of normal male and female bone. Possible involvement of osteocalcin in bone remodeling. J Clin Invest 93, 989, 1994.

63. Smith, C., Craig, O., Prigodich, R., Nielsen-Marsh, C., Jans, M., Vermeer, C., and Collins, M. Diagenesis and survival of osteocalcin in archaeological bone. J Archaeol Sci 32, 105, 2005. 
64. Eppell, S.J., Tong, W., Katz, J.L., Kuhn, L., and Glimcher, M.J. Shape and size of isolated bone mineralites measured using atomic force microscopy. J Orthop Res 19, 1027, 2001.

65. Grabner, B., Landis, W.J., Roschger, P., Rinnerthaler, S., Peterlik, H., Klaushofer, K., and Fratzl, P. Age- and genotype-dependence of bone material properties in the osteogenesis imperfecta murine model (oim). Bone 29, 453, 2001.

66. Olszta, M.J., Cheng, X., Jee, S.S., Kumar, R., Kim, Y.-Y., Kaufman, M.J., Douglas, E.P., and Gower, L.B. Bone structure and formation: A new perspective. Mater Sci Eng R Rep 58, 77, 2007.

67. Boskey, A.L. Matrix proteins and mineralization: an overview. Connect Tissue Res 35, 357, 1996.

68. Chai, Y.C., Carlier, A., Bolander, J., Roberts, S.J., Geris, L., Schrooten, J., Oosterwyck, H.V., and Luyten, F.P. Current views on calcium phosphate osteogenicity and the translation into effective bone regeneration strategies. Acta Biomater 8, 3876, 2012.

69. Stubbs, J.T., Mintz, K.P., Eanes, E.D., Torchia, D.A., and Fisher, L.W. Characterization of native and recombinant bone sialoprotein: delineation of the mineral-binding and cell adhesion domains and structural analysis of the RGD domain. J Bone Miner Res 12, 1210, 1997.

70. He, G., Ramachandran, A., Dahl, T., George, S., Schultz, D., Cookson, D., Veis, A., and George, A. Phosphorylation of phosphophoryn is crucial for its function as a mediator of biomineralization. J Biol Chem 280, 33109, 2005.

71. Monfoulet, L., Malaval, L., Aubin, J.E., Rittling, S.R., Gadeau, A.P., Fricain, J.C., and Chassande, O. Bone sialoprotein, but not osteopontin, deficiency impairs the mineralization of regenerating bone during cortical defect healing. Bone 46, 447, 2010.

72. Meyer, U., Meyer, T., Vosshans, J., and Joos, U. Decreased expression of osteocalcin and osteonectin in relation to high strains and decreased mineralization in mandibular distraction osteogenesis. J Craniomaxillofac Surg 27, 222, 1999.

73. Hoang, Q.Q., Sicheri, F., Howard, A.J., and Yang, D.S. Bone recognition mechanism of porcine osteocalcin from crystal structure. Nature 425, 977, 2003.

74. Roach, H.I. Why does bone matrix contain non-collagenous proteins? The possible roles of osteocalcin, osteonectin, osteopontin and bone sialoprotein in bone mineralization and resorption. Cell Biol Int 18, 617, 1994.

75. Rosenthal, A.K., Gohr, C.M., Uzuki, M., and Masuda, I. Osteopontin promotes pathologic mineralization in articular cartilage. Matrix Biol 26, 96, 2007.

76. Elangovan, S., Margolis, H.C., Oppenheim, F.G., and Beniash, E. Conformational changes in salivary proline-rich protein 1 upon adsorption to calcium phosphate crystals. Langmuir 23, 11200, 2007.

77. Orgel, J.P., Irving, T.C., Miller, A., and Wess, T.J. Microfibrillar structure of type I collagen in situ. Proc Natl Acad Sci U S A 103, 9001, 2006.

78. Minary-Jolandan, M., and Yu, M.F. Nanomechanical heterogeneity in the gap and overlap regions of type I collagen fibrils with implications for bone heterogeneity. Biomacromolecules 10, 2565, 2009.

79. Veis, A. Mineralization in organic matrix frameworks. Rev Miner Geochem 54, 249, 2003.

80. Dahl, T., Sabsay, B., and Veis, A. Type I collagenphosphophoryn interactions: Specificity of the monomermonomer binding. J Struct Biol 123, 162, 1998.

81. Beniash, E., Traub, W., Veis, A., and Weiner, S. A transmission electron microscope study using vitrified ice sec- tions of predentin: structural changes in the dentin collagenous matrix prior to mineralization. J Struct Biol 132, $212,2000$.

82. He, G., and George, A. Dentin matrix protein 1 immobilized on type I collagen fibrils facilitates apatite deposition in vitro. J Biol Chem 279, 11649, 2004.

83. Plate, U., Arnold, S., Reimer, L., Höhling, H.J., and Boyde, A. Investigation of the early mineralisation on collagen in dentine of rat incisors by quantitative electron spectroscopic diffraction (ESD). Cell Tissue Res 278, 543, 1994.

84. Arnold, S., Plate, U., Wiesmann, H.P., Stratmann, U., Kohl, H., and Höhling, H.J. Quantitative electron spectroscopic diffraction analyses of the crystal formation in dentine. J Microsc 195, 58, 1999.

85. Toroian, D., Lim, J.E., and Price, P.A. The size exclusion characteristics of type I collagen: Implications for the role of noncollagenous bone constituents in mineralization. J Biol Chem 282, 22437, 2007.

86. He, G., Gajjeraman, S., Schultz, D., Cookson, D., Qin, C., Butler, W.T., Hao, J., and George, A. Spatially and temporally controlled biomineralization is facilitated by interaction between self-assembled dentin matrix protein 1 and calcium phosphate nuclei in solution. Biochem 44, 16140, 2005.

87. George, A., and Veis, A. Phosphorylated proteins and control over apatite nucleation, crystal growth and inhibition. Chem Rev 108, 4670, 2008.

88. Gower, L.B. Biomimetic model systems for investigating the amorphous precursor pathway and its role in biomineralization. Chem Rev 108, 4551, 2008.

89. Gebauer, D., Völkel, A., and Cölfen, H. Stable prenucleation calcium carbonate clusters. Science 322, 1819, 2008.

90. Pouget, E.M., Bomans, P.H., Goos, J.A., Frederik, P.M., de With, G., and Sommerdijk, N.A. The initial stages of template-controlled $\mathrm{CaCO}_{3}$ formation revealed by cryo-TEM. Science 323, 1455, 2009.

91. Dey, A., Bomans, P.H., Müller, F.A., Will, J., Frederik, P.M., de With, G., and Sommerdijk, N.A. The role of prenucleation clusters in surface-induced calcium phosphate crystallization. Nat Mater 9, 1010, 2010.

92. Habraken, W.J., Tao, J., Brylka, L.J., Friedrich, H., Bertinetti, L., Schenk, A.S., Verch, A., Dmitrovic, V., Bomans, P.H., Frederik, P.M., Laven, J., van der Schoot, P., Aichmayer, B., de With, G., DeYoreo, J.J., and Sommerdijk, N.A. Ion-association complexes unite classical and non-classical theories for the biomimetic nucleation of calcium phosphate. Nat Commun 4, 1507, 2013.

93. Anderson, H.C. Molecular biology of matrix vesicles. Clin Orthop Relat Res, 266, 1995.

94. Anderson, H.C., Garimella, R., and Tague, S.E. The role of matrix vesicles in growth plate development and biomineralization. Front Biosci 10, 822, 2005.

95. Stewart, A.J., Roberts, S.J., Seawright, E., Davey, M.G., Fleming, R.H., and Farquharson, C. The presence of PHOSPHO1 in matrix vesicles and its developmental expression prior to skeletal mineralization. Bone 39, 1000, 2006.

96. Golub, E.E. Role of matrix vesicles in biomineralization. Biochim Biophys Acta 1790, 1592, 2009.

97. Anderson, H.C., Sipe, J.B., Hessle, L., Dhanyamraju, R., Atti, E., Camacho, N.P., and Millán, J.L. Impaired calcification around matrix vesicles of growth plate and bone in alkaline phosphatase-deficient mice. Am J Pathol 164, 841, 2004. 
98. Siffert, R.S. The role of alkaline phosphatase in osteogenesis. J Exp Med 93, 415, 1951.

99. Golub, E.E., Harrison, G., Taylor, A.G., Camper, S., and Shapiro, I.M. The role of alkaline phosphatase in cartilage mineralization. Bone Miner 17, 273, 1992.

100. Orimo, $\mathrm{H}$. The mechanism of mineralization and the role of alkaline phosphatase in health and disease. J Nippon Med Sch 77, 4, 2010.

101. Houston, B., Stewart, A.J., and Farquharson, C. PHOSPHO1-a novel phosphatase specifically expressed at sites of mineralisation in bone and cartilage. Bone 34, 629, 2004.

102. Roberts, S., Narisawa, S., Harmey, D., Millán, J.L., and Farquharson, C. Functional involvement of PHOSPHO1 in matrix vesicle-mediated skeletal mineralization. J Bone Miner Res 22, 617, 2007.

103. Šupová, M. Problem of hydroxyapatite dispersion in polymer matrices: A review. J Mater Sci Mater Med 20, 1201, 2009.

104. Kickelbick, G. Concepts for the incorporation of inorganic building blocks into organic polymers on a nanoscale. Prog Polym Sci 28, 83, 2003.

105. Holmes, R.L., Campbell, J.A., Burford, R.P., and Karatchevtseva, I. Pyrolysis behaviour of titanium dioxidepoly(vinyl pyrrolidone) composite materials. Polym Degrad Stab 94, 1882, 2009.

106. Toworfe, G.K., Composto, R.J., Shapiro, I.M., and Ducheyne, P. Nucleation and growth of calcium phosphate on amine-, carboxyl- and hydroxyl-silane self-assembled monolayers. Biomaterials 27, 631, 2006.

107. Shen, J.W., Wu, T., Wang, Q., and Pan, H.H. Molecular simulation of protein adsorption and desorption on hydroxyapatite surfaces. Biomaterials 29, 513, 2008.

108. Rees, S.G., Hughes Wassell, D.T., Waddington, R.J., and Embery, G. Interaction of bone proteoglycans and proteoglycan components with hydroxyapatite. Biochim Biophys Acta 1568, 118, 2001.

109. Zhang, S., Gangal, G., and Uludağ, H. 'Magic bullets' for bone diseases: progress in rational design of bone-seeking medicinal agents. Chem Soc Rev 36, 507, 2007.

110. Tiselius, A., Hjertén, S., and Levin, O. Protein chromatography on calcium phosphate columns. Arch Biochem Biophys 65, 132, 1956.

111. Gorbunoff, M.J. The interaction of proteins with hydroxyapatite. I. Role of protein charge and structure. Anal Biochem 136, 425, 1984.

112. Gorbunoff, M.J. The interaction of proteins with hydroxyapatite. II. Role of acidic and basic groups. Anal Biochem 136, 433, 1984.

113. Gorbunoff, M.J., and Timasheff, S.N. The interaction of proteins with hydroxyapatite. III. Mechanism. Anal Biochem 136, 440, 1984.

114. Hlady, V., and Füredi-Milhofer, H. Adsorption of human serum albumin on precipitated hydroxyapatite. J Colloid Interface Sci 69, 460, 1979.

115. Hauschka, P.V., and Carr, S.A. Calcium-dependent $\alpha$-helical structure in osteocalcin. Biochemistry 21, 2538, 1982.

116. Nieuw Amerongen, A.V., Oderkerk, C.H., and Veerman, E.C. Interaction of human salivary mucins with hydroxyapatite. J Biol Buccale 17, 85, 1989.

117. Rathman, W.M., Van Zeyl, M.J., Van den Keybus, P.A., Bank, R.A., Veerman, E.C., and Nieuw Amerongen, A.V. Isolation and characterization of three non-mucinous human salivary proteins with affinity for hydroxyapatite. J Biol Buccale 17, 199, 1989.
118. Robinson, C., Connell, S., Brookes, S.J., Kirkham, J., Shore, R.C., and Smith, D.A. Surface chemistry of enamel apatite during maturation in relation to $\mathrm{pH}$ : Implications for protein removal and crystal growth. Arch Oral Biol 50, 267, 2005.

119. Rhee, S.H., Lee, J.D., and Tanaka, J. Nucleation of hydroxyapatite crystal through chemical interaction with collagen. J Am Ceram Soc 83, 2890, 2000.

120. Chang, M.C. Organic-inorganic interaction between hydroxyapatite and gelatin with the aging of gelatin in aqueous phosphoric acid solution. J Mater Sci Mater Med 19, 3411, 2008.

121. Chang, M.C., Ikoma, T., Kikuchi, M., and Tanaka, J. Preparation of a porous hydroxyapatite/collagen nanocomposite using glutaraldehyde as a crosslinkage agent. J Mater Sci Lett 20, 1199, 2001.

122. Chang, M.C., Ko, C.C., and Douglas, W.H. Preparation of hydroxyapatite-gelatin nanocomposite. Biomaterials 24, 2853, 2003.

123. Chirila, T.V., Minamisawa, T., Keen, I., and Shiba, K. Effect of motif-programmed artificial proteins on the calcium uptake in a synthetic hydrogel. Macromol Biosci 9, 959, 2009.

124. Shiba, K., and Minamisawa, T. A synthesis approach to understanding repeated peptides conserved in mineralization proteins. Biomacromolecules 8, 2659, 2007.

125. Tsuji, T., Onuma, K., Yamamoto, A., Iijima, M., and Shiba, K. Direct transformation from amorphous to crystalline calcium phosphate facilitated by motif-programmed artificial proteins. Proc Natl Acad Sci U S A 105, 16866, 2008.

126. Wheeler, A.P., George, J.W., and Evans, C.A. Control of calcium carbonate nucleation and crystal growth by soluble matrx of oyster shell. Science 212, 1397, 1981.

127. Jee, S.S., Culver, L., Li, Y., Douglas, E.P., and Gower, L.B. Biomimetic mineralization of collagen via an enzyme-aided PILP process. J Cryst Growth 312, 1249, 2010.

128. Jee, S.S., Thula, T.T., and Gower, L.B. Development of bone-like composites via the polymer-induced liquidprecursor (PILP) process. Part 1: influence of polymer molecular weight. Acta Biomater 6, 3676, 2010.

129. Delaittre, G., Greiner, A.M., Pauloehrl, T., Bastmeyer, M., and Barner-Kowollik, C. Chemical approaches to synthetic polymer surface biofunctionalization for targeted cell adhesion using small binding motifs. Soft Matter 8, 7323, 2012.

130. Hynes, R.O. The extracellular matrix: not just pretty fibrils. Science 326, 1216, 2009.

131. Pozzi, A., and Zent, R. Integrins: sensors of extracellular matrix and modulators of cell function. Nephron Exp Nephrol 94, e77, 2003.

132. Ruoslahti, E. RGD and other recognition sequences for integrins. Annu Rev Cell Dev Biol 12, 697, 1996.

133. Schwartz, M.A. Integrin signaling revisited. Trends Cell Biol 11, 466, 2001

134. Hersel, U., Dahmen, C., and Kessler, H. RGD modified polymers: biomaterials for stimulated cell adhesion and beyond. Biomaterials 24, 4385, 2003.

135. Ito, Y., Kajihara, M., and Imanishi, Y. Materials for enhancing cell adhesion by immobilization of cell-adhesive peptide. J Biomed Mater Res 25, 1325, 1991.

136. Hlady, V.V., and Buijs, J. Protein adsorption on solid surfaces. Curr Opin Biotechnol 7, 72, 1996.

137. Iuliano, D.J., Saavedra, S.S., and Truskey, G.A. Effect of the conformation and orientation of adsorbed fibronectin on endothelial cell spreading and the strength of adhesion. J Biomed Mater Res 27, 1103, 1993. 
138. Lhoest, J.B., Detrait, E., van den Bosch de Aguilar, P., and Bertrand, P. Fibronectin adsorption, conformation, and orientation on polystyrene substrates studied by radiolabeling, XPS, and ToF SIMS. J Biomed Mater Res 41, 95, 1998.

139. Barker, T.H. The role of ECM proteins and protein fragments in guiding cell behavior in regenerative medicine. Biomaterials 32, 4211, 2011.

140. Bellis, S.L. Advantages of RGD peptides for directing cell association with biomaterials. Biomaterials 32, 4205, 2011.

141. Collier, J.H., and Segura, T. Evolving the use of peptides as components of biomaterials. Biomaterials 32, 4198, 2011.

142. Lucchese, G., Stufano, A., Trost, B., Kusalik, A., and Kanduc, D. Peptidology: short amino acid modules in cell biology and immunology. Amino Acids 33, 703, 2007.

143. Ratcliffe, A. Difficulties in the translation of functionalized biomaterials into regenerative medicine clinical products. Biomaterials 32, 4215, 2011.

144. Williams, D.F. The role of short synthetic adhesion peptides in regenerative medicine; the debate. Biomaterials 32, 4195, 2011.

145. Itoh, D., Yoneda, S., Kuroda, S., Kondo, H., Umezawa, A., Ohya, K., Ohyama, T., and Kasugai, S. Enhancement of osteogenesis on hydroxyapatite surface coated with synthetic peptide (EEEEEEEPRGDT) in vitro. J Biomed Mater Res 62, 292, 2002.

146. Fujisawa, R., Wada, Y., Nodasaka, Y., and Kuboki, Y. Acidic amino acid-rich sequences as binding sites of osteonectin to hydroxyapatite crystals. Biochim Biophys Acta 1292, 53, 1996.

147. Kasugai, S., Fujisawa, R., Waki, Y., Miyamoto, K., and Ohya, K. Selective drug delivery system to bone: small peptide (Asp) 6 conjugation. J Bone Miner Res 15, 936, 2000.

148. Sarvestani, A.S., He, X., and Jabbari, E. Effect of osteonectin-derived peptide on the viscoelasticity of hydrogel/ apatite nanocomposite scaffolds. Biopolymers 85, 370, 2007.

149. Sarvestani, A.S., He, X., and Jabbari, E. Osteonectin-derived peptide increases the modulus of a bone-mimetic nanocomposite. Eur Biophys J 37, 229, 2008.

150. Culpepper, B.K., Phipps, M.C., Bonvallet, P.P., and Bellis, S.L. Enhancement of peptide coupling to hydroxyapatite and implant osseointegration through collagen mimetic peptide modified with a polyglutamate domain. Biomaterials 31, 9586, 2010.

151. Culpepper, B.K., Bonvallet, P.P., Reddy, M.S., Ponnazhagan, S., and Bellis, S.L. Polyglutamate directed coupling of bioactive peptides for the delivery of osteoinductive signals on allograft bone. Biomaterials 34, 1506, 2013.

152. Murphy, M.B., Hartgerink, J.D., Goepferich, A., and Mikos, A.G. Synthesis and in vitro hydroxyapatite binding of peptides conjugated to calcium-binding moieties. Biomacromolecules 8, 2237, 2007.

153. Yang, X., Xie, B., Wang, L., Qin, Y., Henneman, Z.J., and Nancollas, G.H. Influence of magnesium ions and amino acids on the nucleation and growth of hydroxyapatite. Cryst Eng Comm 13, 1153, 2011.

154. Bleek, K., and Taubert, A. New developments in polymercontrolled, bioinspired calcium phosphate mineralization from aqueous solution. Acta Biomater 9, 6283, 2013.

155. Palazzo, B., Walsh, D., Iafisco, M., Foresti, E., Bertinetti, L., Martra, G., Bianchi, C.L., Cappelletti, G., and Roveri, N. Amino acid synergetic effect on structure, morphology and surface properties of biomimetic apatite nanocrystals. Acta Biomater 5, 1241, 2009.
156. Boanini, E., Torricelli, P., Gazzano, M., Giardino, R., and Bigi, A. Nanocomposites of hydroxyapatite with aspartic acid and glutamic acid and their interaction with osteoblast-like cells. Biomaterials 27, 4428, 2006.

157. Furuichi, K., Oaki, Y., Ichimiya, H., Komotori, J., and Imai, H. Preparation of hierarchically organized calcium phosphate-organic polymer composites by calcification of hydrogel. Sci Technol Adv Mater 7, 219, 2006.

158. Imai, H., Tatara, S., Furuichi, K., and Oaki, Y. Formation of calcium phosphate having a hierarchically laminated architecture through periodic precipitation in organic gel. Chem Commun (Camb) 15, 1952, 2003.

159. Gkioni, K., Leeuwenburgh, S.C., Douglas, T.E., Mikos, A.G., and Jansen, J.A. Mineralization of hydrogels for bone regeneration. Tissue Eng Part B Rev 16, 577, 2010.

160. Hu, Y.Y., Rawal, A., and Schmidt-Rohr, K. Strongly bound citrate stabilizes the apatite nanocrystals in bone. Proc Natl Acad Sci U S A 107, 22425, 2010.

161. Hu, Y.Y., Liu, X.P., Ma, X., Rawal, A., Prozorov, T., Akinc, M., Mallapragada, S.K., and Schmidt-Rohr, K. Biomimetic self-assembling copolymer-hydroxyapatite nanocomposites with the nanocrystal size controlled by citrate. Chem Mater 23, 2481, 2011.

162. López-Macipe, A., Gómez-Morales, J., and RodríguezClemente, R. Nanosized hydroxyapatite precipitation from homogeneous calcium/citrate/phosphate solutions using microwave and conventional heating. Adv Mater 10, 49, 1998.

163. Martins, M.A., Santos, C., Almeida, M.M., and Costa, M.E. Hydroxyapatite micro- and nanoparticles: nucleation and growth mechanisms in the presence of citrate species. J Colloid Interface Sci 318, 210, 2008.

164. Sun, T., Hayakawa, K., Bateman, K.S., and Fraser, M.E. Identification of the citrate-binding site of human ATPcitrate lyase using X-ray crystallography. J Biol Chem 285, 27418, 2010.

165. Leeuwenburgh, S.C., Ana, I.D., and Jansen, J.A. Sodium citrate as an effective dispersant for the synthesis of inorganic-organic composites with a nanodispersed mineral phase. Acta Biomater 6, 836, 2010.

166. Phadke, A., Zhang, C., Hwang, Y., Vecchio, K., and Varghese, S. Templated mineralization of synthetic hydrogels for bone-like composite materials: Role of matrix hydrophobicity. Biomacromolecules 11, 2060, 2010.

167. Badiger, M., Lele, A., Bhalerao, V., Varghese, S., and Mashelkar, R. Molecular tailoring of thermoreversible copolymer gels: some new mechanistic insights. J Chem Phys 109, 1175, 1998.

168. Varghese, S., Lele, A.K., Srinivas, D., and Mashelkar, R.A. Role of hydrophobicity on structure of polymer-metal complexes. J Phys Chem B 105, 5368, 2001.

169. Song, J., Saiz, E., and Bertozzi, C.R. A new approach to mineralization of biocompatible hydrogel scaffolds: an efficient process toward 3-dimensional bonelike composites. J Am Chem Soc 125, 1236, 2003.

170. Bigi, A., Boanini, E., Panzavolta, S., and Roveri, N. Biomimetic growth of hydroxyapatite on gelatin films doped with sodium polyacrylate. Biomacromolecules 1, 752, 2000.

171. Cha, C., Kim, E.S., Kim, I.W., and Kong, H. Integrative design of a poly(ethylene glycol)-poly(propylene glycol)alginate hydrogel to control three dimensional biomineralization. Biomaterials 32, 2695, 2011.

172. Suzuki, S., Whittaker, M.R., Grøndahl, L., Monteiro, M.J., and Wentrup-Byrne, E. Synthesis of soluble phosphate 
polymers by RAFT and their in vitro mineralization. Biomacromolecules 7, 3178, 2006.

173. Chirila, T.V., Zainuddin, Hill, D.J., Whittaker, A.K., and Kemp, A. Effect of phosphate functional groups on the calcification capacity of acrylic hydrogels. Acta Biomater 3, 95, 2007.

174. Kim, C.W., Kim, S.E., Kim, Y.W., Lee, H.J., Choi, H.W., Chang, J.H., Choi, J., Kim, K.J., Shim, K.B., Jeong, Y.K., and Lee, S.C. Fabrication of hybrid composites based on biomineralization of phosphorylated poly(ethylene glycol) hydrogels. J Mater Res 24, 50, 2009.

175. Song, J., Malathong, V., and Bertozzi, C.R. Mineralization of synthetic polymer scaffolds: A bottom-up approach for the development of artificial bone. J Am Chem Soc 127, 3366, 2005.

176. Addison, W.N., Miller, S.J., Ramaswamy, J., Mansouri, A., Kohn, D.H., and McKee, M.D. Phosphorylation-dependent mineral-type specificity for apatite-binding peptide sequences. Biomaterials 31, 9422, 2010.

177. Sailaja, G.S., Ramesh, P., and Varma, H.K. Ultrastructural evaluation of in vitro mineralized calcium phosphate phase on surface phosphorylated poly(hydroxy ethyl methacrylate-co-methyl methacrylate). J Mater Sci Mater Med 21, 1183, 2010.

178. Gu, L.S., Kim, J., Kim, Y.K., Liu, Y., Dickens, S.H., Pashley, D.H., Ling, J.Q., and Tay, F.R. A chemical phosphorylationinspired design for type I collagen biomimetic remineralization. Dent Mater 26, 1077, 2010.

179. Gu, L.S., Kim, Y.K., Liu, Y., Takahashi, K., Arun, S., Wimmer, C.E., Osorio, R., Ling, J.Q., Looney, S.W., Pashley, D.H., and Tay, F.R. Immobilization of a phosphonated analog of matrix phosphoproteins within crosslinked collagen as a templating mechanism for biomimetic mineralization. Acta Biomater 7, 268, 2011.

180. Fernández, D., Vega, D., and Goeta, A. The calcium-binding properties of pamidronate, a bone-resorption inhibitor. Acta Crystallogr C 58, m494, 2002.

181. Fernández, D., Vega, D., and Goeta, A. Alendronate zwitterions bind to calcium cations arranged in columns. Acta Crystallogr C 59, m543, 2003.

182. Yang, X., Akhtar, S., Rubino, S., Leifer, K., Hilborn, J., and Ossipov, D. Direct "click" synthesis of hybrid bisphosphonate-hyaluronic acid hydrogel in aqueous solution for biomineralization. Chem Mater 24, 1690, 2012.

183. Radeva, T., and Petkanchin, I.I. Electric properties and conformation of polyethylenimine at the hematite-aqueous solution interface. J Colloid Interface Sci 196, 87, 1997.

184. Mészáros, R., Thompson, L., Bos, M., and de Groot, P. Adsorption and electrokinetic properties of polyethylenimine on silica surfaces. Langmuir 18, 6164, 2002.

185. Zhang, S., Wright, J.E., Özber, N., and Uludağ, H. The interaction of cationic polymers and their bisphosphonate derivatives with hydroxyapatite. Macromol Biosci 7, 656, 2007.

186. Wang, D., Miller, S., Sima, M., Kopečková, P., and Kopeček, J. Synthesis and evaluation of water-soluble poly- meric bone-targeted drug delivery systems. Bioconjug Chem 14, 853, 2003.

187. Wang, D., Miller, S.C., Kopečková, P., and Kopeček, J. Bone-targeting macromolecular therapeutics. Adv Drug Deliv Rev 57, 1049, 2005.

188. Wang, G., Kucharski, C., Lin, X., and Uludağ, H. Bisphosphonate-coated BSA nanoparticles lack bone targeting after systemic administration. J Drug Target 18, 611, 2010.

189. Wang, G., Mostafa, N.Z., Incani, V., Kucharski, C., and Uludağ, H. Bisphosphonate-decorated lipid nanoparticles designed as drug carriers for bone diseases. J Biomed Mater Res A 100, 684, 2012.

190. Boanini, E., Gazzano, M., Rubini, K., and Bigi, A. Composite nanocrystals provide new insight on alendronate interaction with hydroxyapatite structure. Adv Mater 19, 2499, 2007.

191. Jung, A., Bisaz, S., and Fleisch, H. The binding of pyrophosphate and two diphosphonates by hydroxyapatite crystals. Calcif Tissue Res 11, 269, 1973.

192. Rogers, M.J., Watts, D.J., and Russell, R.G. Overview of bisphosphonates. Cancer 80, 1652, 1997.

193. Hutchens, S.A., Benson, R.S., Evans, B.R., O'Neill, H.M., and Rawn, C.J. Biomimetic synthesis of calcium-deficient hydroxyapatite in a natural hydrogel. Biomaterials 27, 4661, 2006.

194. Kawai, T., Ohtsuki, C., Kamitakahara, M., Hosoya, K., Tanihara, M., Miyazaki, T., Sakaguchi, Y., and Konagaya, $\mathrm{S}$. In vitro apatite formation on polyamide containing carboxyl groups modified with silanol groups. J Mater Sci Mater Med 18, 1037, 2007.

195. Ryu, J., Ku, S.H., Lee, H., and Park, C.B. Mussel-inspired polydopamine coating as a universal route to hydroxyapatite crystallization. Adv Funct Mater 20, 2132, 2010.

196. Douglas, T., Wlodarczyk, M., Pamula, E., Declercq, H., de Mulder, E., Bucko, M., Balcaen, L., Vanhaecke, F., Cornelissen, R., Dubruel, P., Jansen, J., and Leeuwenburgh, S. Enzymatic mineralization of gellan gum hydrogel for bone tissue-engineering applications and its enhancement by polydopamine. J Tissue Eng Regen Med 2012 [Epub ahead of print]; DOI: 10.1002/term.1616.

197. Chang, M.C. Modification of hydroxyapatite/gelatin nanocomposite with the addition of chondroitin sulfate. J Korean Ceram Soc 45, 573, 2008.

Address correspondence to: Sander C.G. Leeuwenburgh, PhD Department of Biomaterials Radboud University Nijmegen Medical Centre P.O. Box 9101 6500 HB Nijmegen The Netherlands

E-mail: s.leeuwenburgh@dent.umcn.nl

Received: April 7, 2013

Accepted: July 26, 2013

Online Publication Date: September 13, 2013 